\title{
Wire Arc Additive Manufacturing: Review on Recent Findings and Challenges in Industrial Applications and Materials Characterization
}

\author{
Mukti Chaturvedi ${ }^{1}$, Elena Scutelnicu ${ }^{2, *(\mathbb{D}}$, Carmen Catalina Rusu ${ }^{2}{ }^{-}$, Luigi Renato Mistodie ${ }^{2}$, \\ Danut Mihailescu ${ }^{2}$ and Arungalai Vendan Subbiah ${ }^{1}$ \\ 1 Department of Electronics and Communication, School of Engineering, Dayananda Sagar University, \\ Bangalore 560114, India; muktichaturvedi.res-soe-ece@dsu.edu.in (M.C.); arungalai-ece@dsu.edu.in (A.V.S.) \\ 2 Manufacturing Engineering Department, Faculty of Engineering, "Dunarea de Jos” University of Galati, \\ 800008 Galati, Romania; carmen.rusu@ugal.ro (C.C.R.); luigi.mistodie@ugal.ro (L.R.M.); \\ danut.mihailescu@ugal.ro (D.M.) \\ * Correspondence: elena.scutelnicu@ugal.ro
}

check for updates

Citation: Chaturvedi, M.; Scutelnicu, E.; Rusu, C.C.; Mistodie, L.R.; Mihailescu, D.; Subbiah, A.V. Wire Arc Additive Manufacturing: Review on Recent Findings and Challenges in Industrial Applications and Materials Characterization. Metals 2021, 11, 939 https://doi.org/10.3390/met11060939

Academic Editors: Elena Gordo and Reza Ghomashchi

Received: 19 May 2021

Accepted: 7 June 2021

Published: 9 June 2021

Publisher's Note: MDPI stays neutral with regard to jurisdictional claims in published maps and institutional affiliations.

Copyright: (c) 2021 by the authors. Licensee MDPI, Basel, Switzerland. This article is an open access article distributed under the terms and conditions of the Creative Commons Attribution (CC BY) license (https:// creativecommons.org/licenses/by/ $4.0 /)$.

\begin{abstract}
Wire arc additive manufacturing (WAAM) is a fusion manufacturing process in which the heat energy of an electric arc is employed for melting the electrodes and depositing material layers for wall formation or for simultaneously cladding two materials in order to form a composite structure. This directed energy deposition-arc (DED-arc) method is advantageous and efficient as it produces large parts with structural integrity due to the high deposition rates, reduced wastage of raw material, and low consumption of energy in comparison with the conventional joining processes and other additive manufacturing technologies. These features have resulted in a constant and continuous increase in interest in this modern manufacturing technique which demands further studies to promote new industrial applications. The high demand for WAAM in aerospace, automobile, nuclear, moulds, and dies industries demonstrates compatibility and reflects comprehensiveness. This paper presents a comprehensive review on the evolution, development, and state of the art of WAAM for non-ferrous materials. Key research observations and inferences from the literature reports regarding the WAAM applications, methods employed, process parameter control, optimization and process limitations, as well as mechanical and metallurgical behavior of materials have been analyzed and synthetically discussed in this paper. Information concerning constraints and enhancements of the wire arc additive manufacturing processes to be considered in terms of wider industrial applicability is also presented in the last part of this paper.
\end{abstract}

Keywords: WAAM; additive manufacturing; heat sources; materials characterisation; optimization models

\section{Introduction}

Considered to be a derivative of the additive manufacturing process, the wire arc additive manufacturing (WAAM) method adopts some of the prominent features of arc welding to implement additive manufacturing (AM) and shows superior performance over conventional joining techniques. WAAM performs layer by layer deposition of weld beads, resulting in a metallic wall with a minimum width of 1-2 $\mathrm{mm}$ [1], followed by build machining to obtain a smooth surface. This resembles cladding in which the successive deposition of the wire feedstock is carried out over a substrate that may be a part of the final build or may be removed by the machining process. The welding technology that can be employed in WAAM is MIG, TIG or plasma arc welding [2,3] respectively illustrated in Figure 1. The automated WAAM process involves a sequence of steps for obtaining the required build characteristics (Figure 2). WAAM is characterised by high deposition rates, capacity to manufacture larger geometries, compatibility with different arc heat sources, as well as weld torch movements and alignments $[4,5]$. Nevertheless, the residual stress and 
the distortion developed are evident in the WAAM samples, similar to the ones generated during additive manufacturing (AM) or welding.

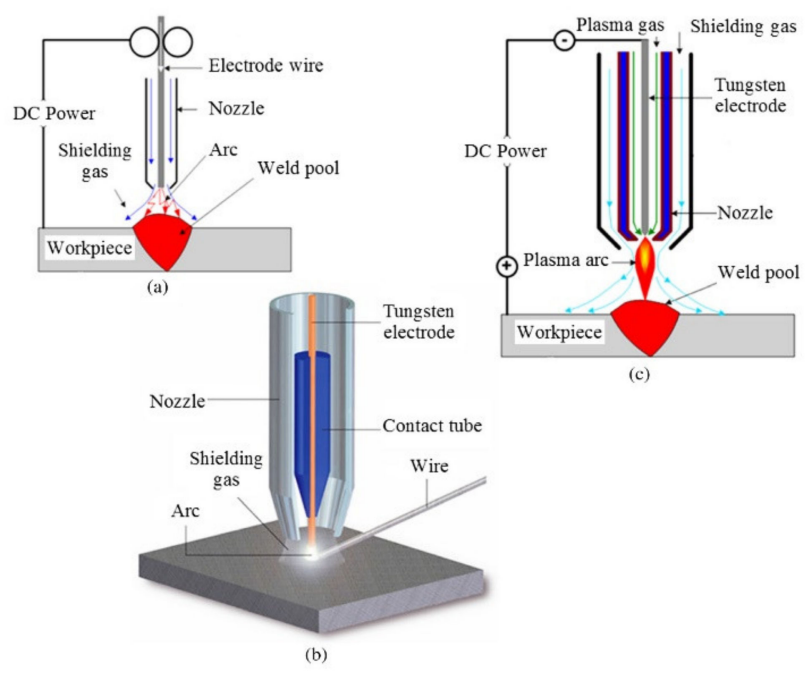

Figure 1. Wire Arc Additive Manufacturing. Principle of WAAM with: (a) MIG; (b) TIG; (c) Plasma Arc Welding. Reprinted from Ref. [6].

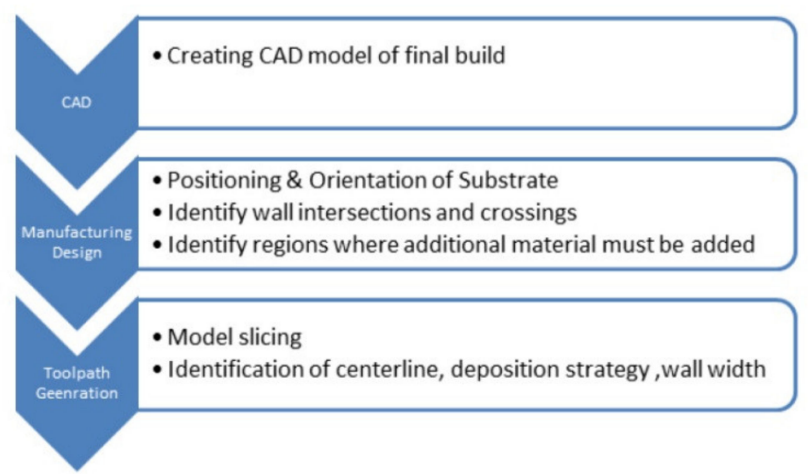

Figure 2. Automated Planning Sequence for WAAM.

WAAM shows feasibility for component manufacturing with a wide range of materials, such as Ti-based alloys, stainless steel, $\mathrm{Ni}$, bronze, $\mathrm{Ta}$, and Al. WAAM in its basic form comprises the arc generation and its movement, a wire feed system, and a substrate clamped to hold its position in order to enable precise deposition. This is accomplished either by applying the cold metal transfer (CMT) technique for the gas tungsten arc welding (GTAW) process or by using plasma transfer [2,3].

Research on WAAM may explore new design techniques aiming to extend process feasibility for functional material grading and making parts with embedded features. Precise control and automation may be executed through controlled mechanisms, parametric optimization incorporating in-situ monitoring, and examination by non-destructive testing. Various design opportunities that can be explored and implemented with WAAM include lightweight construction using $\mathrm{Ti}$ and $\mathrm{Al}$ alloys as filler material, steel as base material for pipe couplings and flanges, nodal joints, and beam reinforcements. Multi-axis deposition could be employed for managing the change in build direction during deposition with the use of a part rotator [7]. The integration of WAAM process and assessments, which are under constant investigation by researchers for further improvements, are illustrated in Figure 3. 


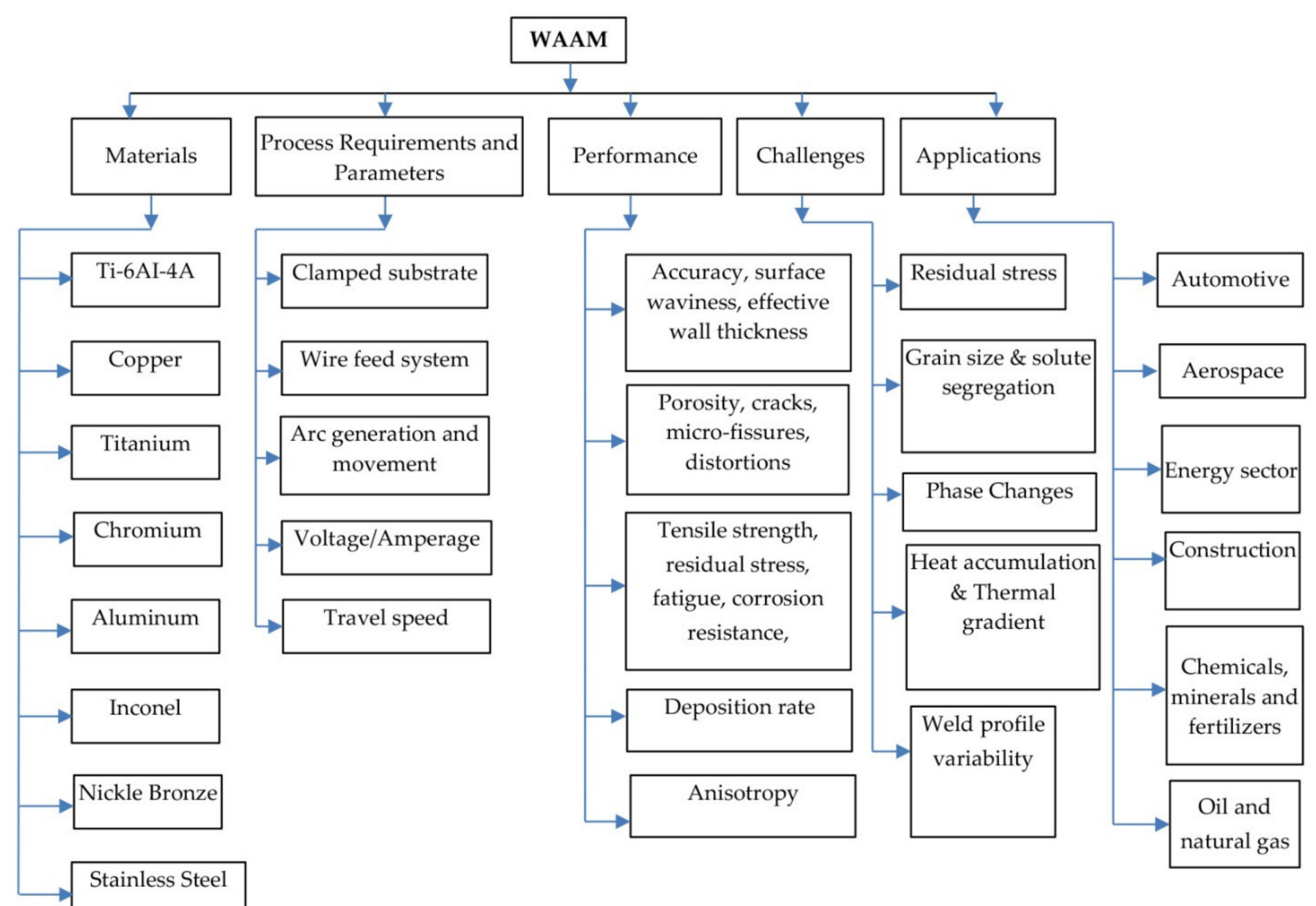

Figure 3. WAAM basics and potential domains of study advancements.

WAAM is also preferred for the minimum resource and energy requirements. All these conducive features promote the applicability of WAAM in the aerospace, aviation, automobile and medical industries. Furthermore, the high deposition rate leads to lower resolution and wavy surface finish, respectively. Caution and preparedness are mandatory while working with WAAM, because of the high heat input that determines a limitation in choosing the materials. Material testing and characterization, performed by appropriate investigation techniques [8,9], as indicated in Figure 4, facilitate the selection of optimal parameters range to achieve higher efficiency of the process and good quality of components fabricated by WAAM. Moreover, the residual stresses and distortion in the structures must be mitigated through a well-designed monitoring and control mechanism. The accumulation of residual stresses is reduced [10] by preheating, heat input decrease, and by increasing the welding speed. It is generally observed that thick substrates increase stress at the substrate-deposit interface. Engineering structures with residual stresses are prone to the initiation of cracks or accelerated growth of pre-existing insignificant cracks during service. Accuracy and surface roughness are other factors which limit the integrity of the WAAM builds. Guidelines, mechanisms, and material selection criteria need to be devised and followed to address the technical shortcomings of WAAM. 


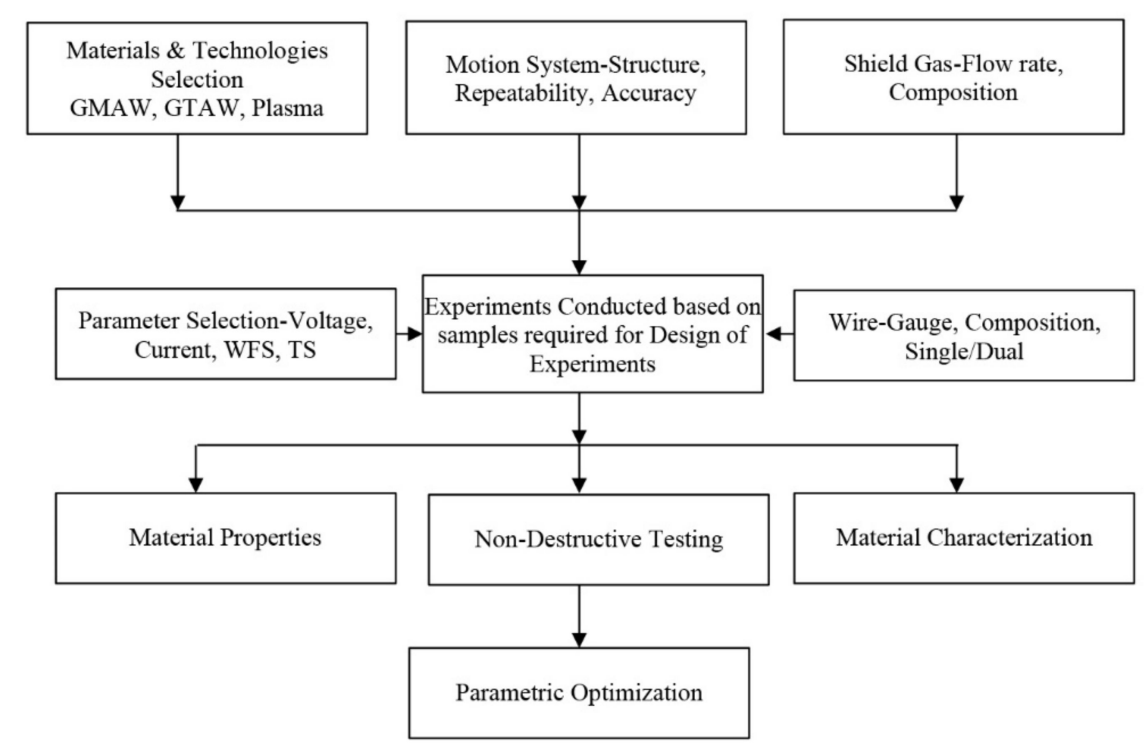

Figure 4. Investigations on WAAM-The Entirety.

\section{WAAM Applications}

This section introduces the investigations reported on WAAM for different materials, design configurations, and application components. WAAM techniques are suitable for materials with high melting points. This section describes the various procedures applied to achieve appropriate mechanical properties in any WAAM application-based components.

Bushachi et al. [11] developed a process map for the implementation of WAAM as a compact system for manufacturing applications for defense platforms which operate in potentially hostile environments that may be restrained due to mission criticality. The authors reported the use of plasma torch with localized shielding, argon recovery equipment, heat treatment mechanism, and a fixed gas distribution system. They addressed the module synchronization to deal with the trade-off between the size of the component and the jig size and suggested the use of anti-vibration bushes to mitigate the issues of vibration.

Lockett et al. [12] proposed a set of design guidelines for WAAM to fabricate aerostructure components. An assessment method was also framed to identify the optimum build orientation. The assessment criteria included substrate waste, deposited material mass, number of deposition operations, build complexity and symmetry. Their experiment with a thicker substrate plate with track flanges, built up using two sided WAAM deposition, yielded favorable results. Rounded corners for continuous deposition and elimination of stress induced at the corners were suggested. They concluded that the WAAM process is not adequate for complex 3D lattices and long thin unsupported members.

Yuan et al. [13] proposed architecture for a multidirectional WAAM system focused on positional bead modelling, multi directional slicing and deposition process optimization strategy. Parabola model was used to obtain optimum welding parameters and desired bead geometry (Figure 5). Based on the experiments, they concluded that a low power and low value of WFS and TS will yield higher quality and improved productivity.

Muller et al. [14] compared gas metal arc weld (GMAW), cold metal transfer (CMT), and cold metal transfer-pulse (CMT-P) processes and proposed a mechanical test approach in which the WAAM built bar was TIG fillet welded between two cylindrical tensile test specimens. This was done to avoid the sample bar banding when it was fixed in the tensile testing equipment. Applying the GMAW method, the highest build up rate and the thickest bar diameter have been achieved. CMT-P yielded favorable results for surface topography, as well as the highest hardness levels, with minimal spatter ignition and lower heat input. 


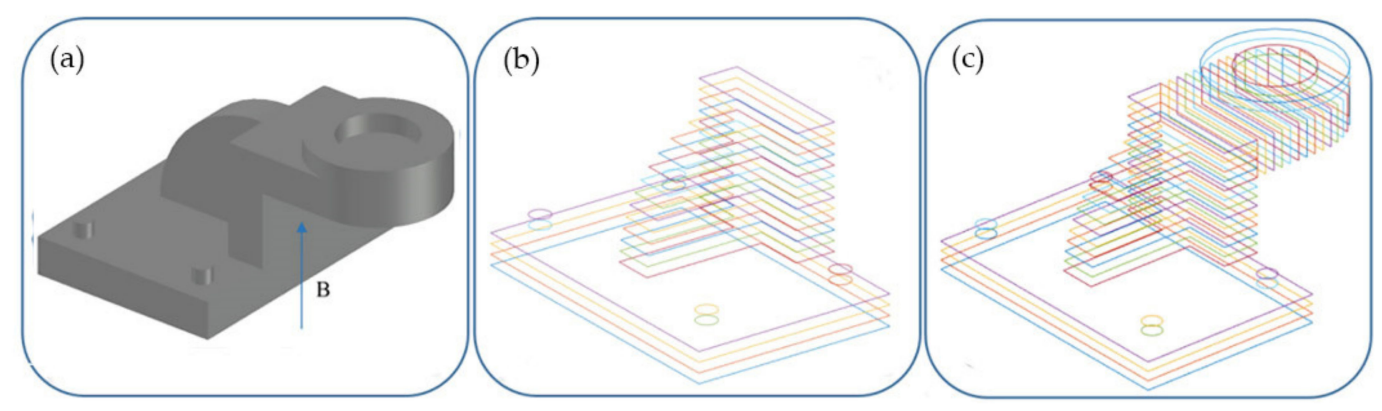

Figure 5. Parabola Mode: (a) Build direction model, (b) Buildable sub-volume without overhang \& (c) complete 3D model. Reprinted from Ref. [13].

Abe et al. [15] developed a computer aided manufacturing (CAM) system taking lattice structure parameters as input for the formation of lattice structures, as shown in Figure 6. The arc discharge time is the key parameter influencing the layer geometry which was inversely proportional to off time while the layer height was proportional to the off time, Figure 7 . The dimensional accuracy was unaffected by the inclination angle.

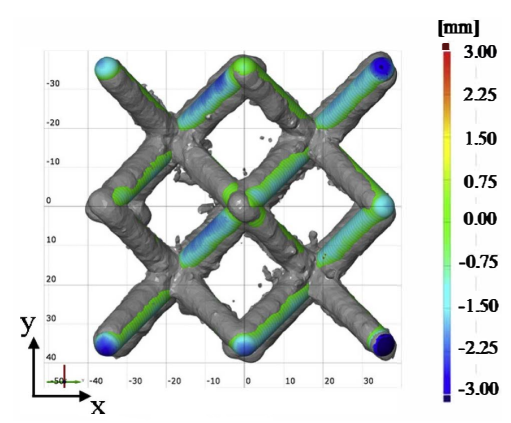

Figure 6. Top view of lattice structure. Reprinted from Ref. [15].

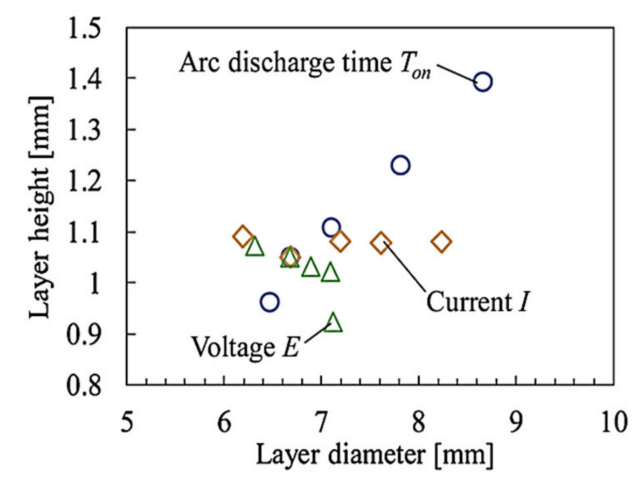

Figure 7. Influence of process parameters on layer geometry. Reprinted from Ref. [15].

Chandrasekaran et al. [16] investigated the suitability of functionally graded material (FGM) fabricated as the optimal material for marine risers using the CMT technique of WAAM. The materials used in the experiment were ER2209 with ER70S-6 C-Mn steel. The tests conducted on the FGM part confirmed higher strength determined by the martensitic formation at the interface and negligible porosity. Figure 8 [16] exhibits the microstructure revealed in carbon-manganese steel (Figure 8a), at the C-Mn steel-duplex SS interface, for different magnifications (Figure 8 b,c). The austenitic bright grains and ferritic dark grains are visible in duplex SS, as Figure 8d shows. Due to the chromium content of 20-22\% present at the interface, the corrosion rate has been improved by 12 times for duplex SS as compared to C-Mn steel. 


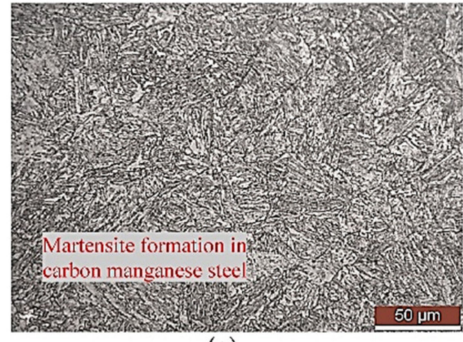

(a)

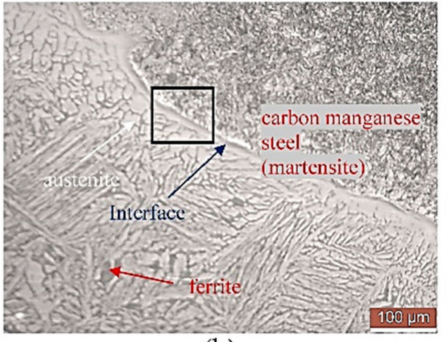

(b)

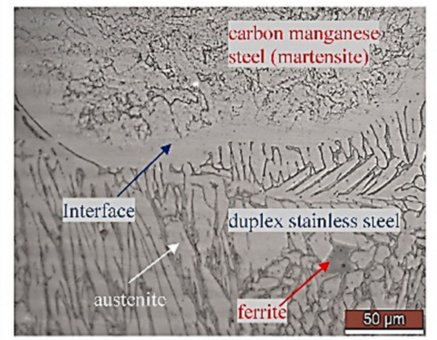

(c)

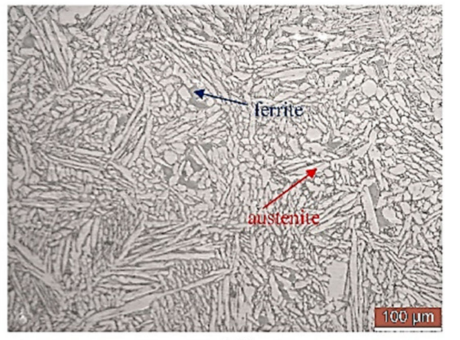

(d)

Figure 8. Microstructure of carbon-manganese and duplex stainless steel joint achieved by CMT technique: (a) in C-Mn steel; (b) at C-Mn steel—duplex SS interface (100 $\mu \mathrm{m}) ;(\mathbf{c})$ at C-Mn steel—duplex SS interface (50 $\mu \mathrm{m})$; (d) in duplex SS. Reprinted with permission from Ref. [16]. Copyright 2020 Elsevier.

Lin et al. [17] studied the tensile properties and elongation of Ti-6Al-4V components manufactured with a high energy density variant of the WAAM process, known as thee continuous plasma arc process. These components are predominantly adopted in structural modules of aircrafts, such as disks and blades of gas turbines.

The WAAM technique is suitable for a number of applications that demand near-net shape, economical manufacturing [18] of large-scale metal parts with design freedom, and relatively high deposition rates. Reduced material waste and fabrication time, as compared to the conventional methods of manufacturing, are additional advantages and open up opportunities for hybrid manufacturing, functionally graded materials, and the production of moderately complex parts with overhangs and integrated functionality. Further research work is imperative to devise methodologies for in-situ process monitoring and control, and to mitigate some of the drawbacks in terms of high heat input rate, residual stress, and porosity.

\section{WAAM Methods}

\subsection{Heat Sources Employed for WAAM}

Researchers have investigated WAAM with a variety of heat sources and customized the heat input mechanism depending on the requirement of the application which are briefly presented in this section. Cold metal transfer (CMT) is the method commonly employed, due to the controlled and efficient heat transfer, and it is implemented in various configurations [19-21]. Prado et al. [19] proposed the integration of CMT and a three-axis $\mathrm{CNC}$ machine to improve the surface quality. An AC servo motor equipped guns without gears led to a high material deposition rate. The current intensity and deposition speed have a great influence on the weld width, but the effect on weld height was considerably less, due to greater amount of material supplied with increased intensity. Zhang et al. [3] analyzed the effect of variable polarity-CMT (VP-CMT) mode on the microstructure and mechanical properties of WAAM Al alloys. Pure CMT mode was found to create equiaxed grains in the YOZ plane and columnar grains in XOZ plane, whereas CMT-P mode had a larger proportion of columnar grains. VP-CMT mode yielded uniform distribution of smaller equiaxed grains having equiaxed dendrites structure. Random value of grain boundary misorientation angle leads to anisotropy of ultimate tensile strength (UTS) in CMT and CMT-P modes. Shukla et al. [20] conducted investigations on the arc behavior in CMT WAAM and highlighted that the welding current is proportional to the plasma distribution width that widens the arc. The variation of the welding arc intensity in the initial layers affects the bead consistency, which is influenced by the reduced thermal gradient in upper layers and the thermal balance between supplied heat input and heat losses.

Xiong et al. [21] investigated a flat position deposition mechanism for inclined thin wall parts, employing a multi-layer single pass GMAW system. The dependence of the inclination angle on the offset distance, wire feed rate, and travel speed were analyzed. The results revealed that the inclination angle is inversely proportional to the field rate and directly proportional to travel speed. 
Researchers also focused on the performance of pulsed [22] or non-pulsed arc [23] on the build performance. Luo et al. [22] analyzed the effect of pulse on arc and droplet transfer. Higher droplet transfer frequency with smaller droplet size was achieved with pulsed arc, which indicated a higher manufacturing efficiency. The tandem torch arrangement was found to be suitable to maintain process stability at high deposition rates. A comparative study of pulsed and non-pulsed arc, made by Zhu et al. [23], showed that pulsed arc and pulsed droplet transfer modes are suitable for the WAAM process. The globular transfer and the spray transfer mode were found to give maximum output power. The pulsed arc and pulsed droplet transfer mode (Figure 9) yielded higher strength, thermal properties, and a high height to width ratio, thereby achieving higher forming efficiency and improved layer deposition.
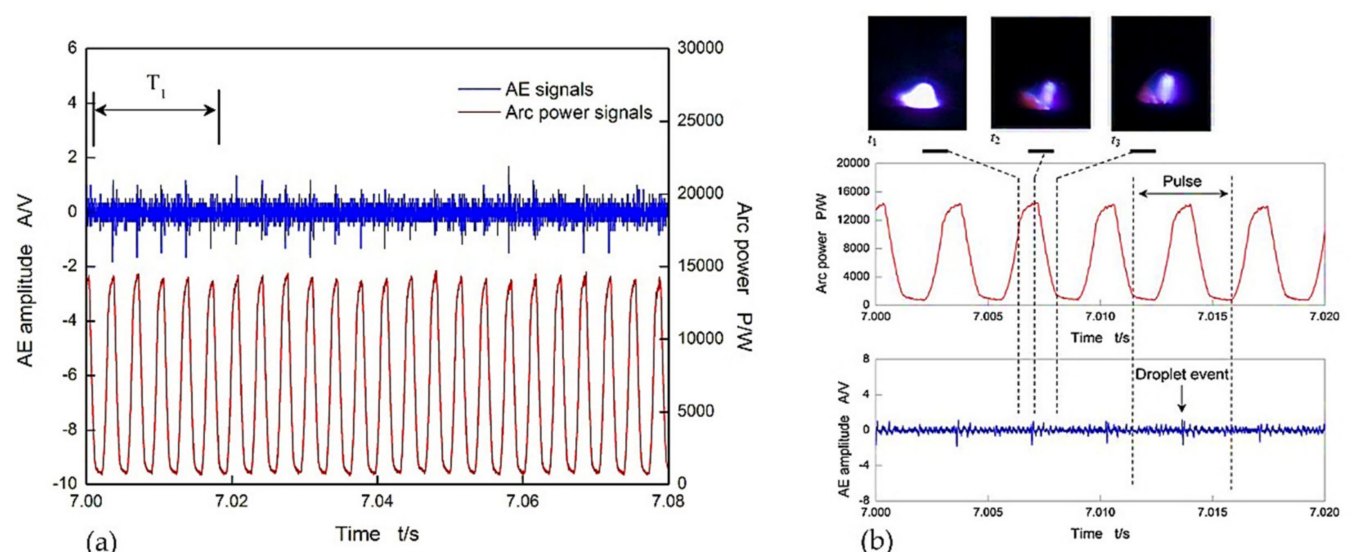

Figure 9. Pulsed arc and Pulsed droplet transfer Mode: (a) Arc power signal and corresponding AE signal and (b) breakup of time T1. Reprinted with permission from Ref. [22]. Copyright 2018 Elsevier.

Rios et al. [2] characterized the plasma transferred arc (PTA) WAAM with respect to various transfer modes depending on the droplet growth time, contact time and weld pool shapes. They concluded that convex weld pool with wire, either in permanent contact or for the time equaling the growth time, generates a stable transfer. This is attributed to the minimization of undesirable fleeting mode having inconsistent droplet transfer. The arc wandering issue in GMAW-WAAM was eliminated in plasma WAAM.

Guo et al. [24] controlled the excessive heat input during the process and introduced the compulsively constricted WAAM. They analyzed the forces acting on the droplets and identified the gravity and the electromagnetic pinch responsible for detachment, while the arc blow and the Lorentz force caused deviation in the droplet's trajectory. Marinelli et al. [25] noticed that the rolling load caused a compressive strain within the previously deposited layers of refractory materials. At the point of peak compressive strain, recrystallisation of the structure was noticed for the depth of three layers below the last deposited layer. This yielded a larger area of equiaxed grains after a number of inter-pass rolling steps. Abe et al. [26] evaluated a lower heat input condition to achieve the desired height to width ratio, by controlling the voltage and monitoring the build temperature.

Huang et al. [27] worked on control of wire feed speed in bypass coupled GMAW WAAM and highlighted the bridging transfer mode, demonstrating fewer fluctuations than the free droplet mode. Besides, the droplet is only subjected to the surface tension when it is in contact with the molten pool. They noticed that an increase in bypass current alters the arc length and shape because of varying the heat input introduced in the workpiece (Figure 10). This phenomenon caused a variation of the droplet diameter and transfer period. The wire feed height is proportional to wire feed speed and this variation determines the droplet transfer mode and changes from the free transfer to the bridging mode (Figure 11). 

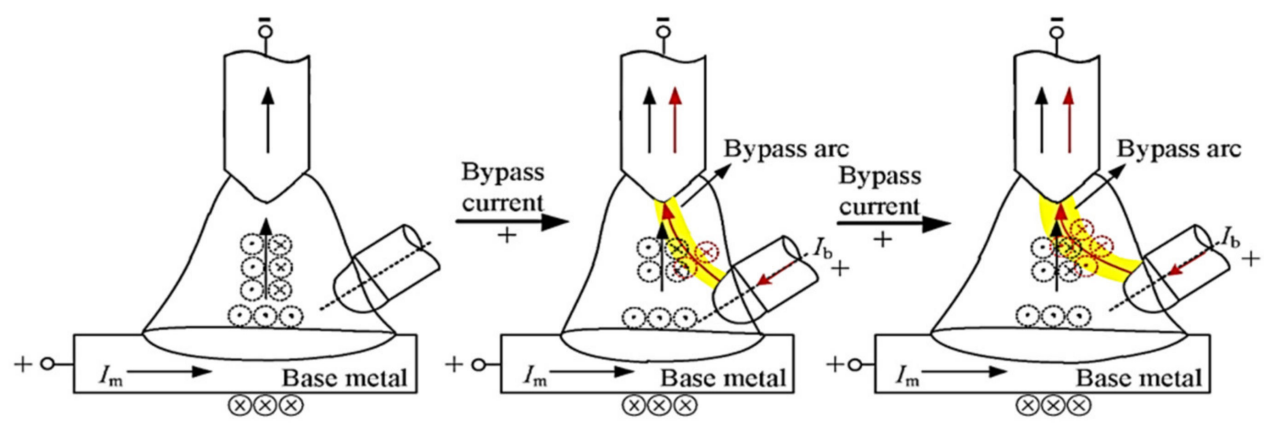

Figure 10. Effect of bypass current on the arc shape. Reprinted from Ref. [27].
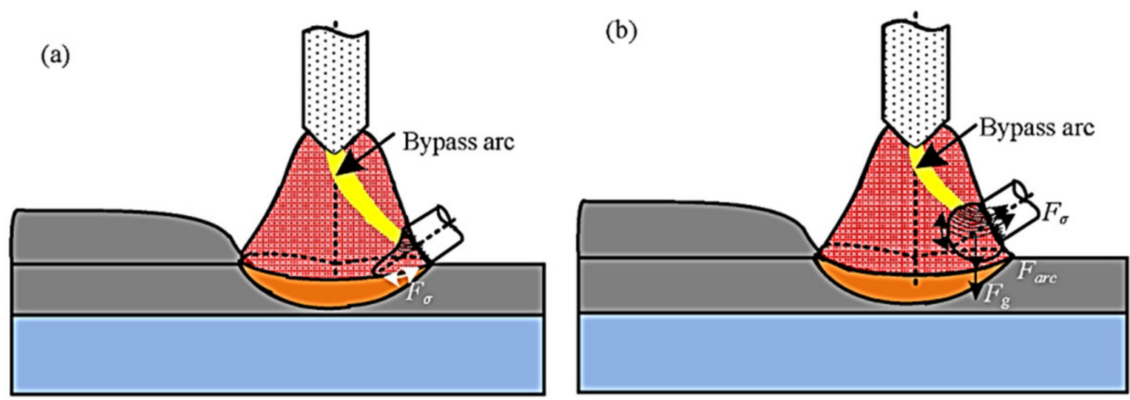

Figure 11. Schematic of force distribution on the droplet: (a) Bridging Transfer; (b) force transfer. Reprinted from Ref. [27].

Li et al. [28] examined WAAM with GMAW heat source for 6366-AA thin wall samples. The effect of shielding gas on weld geometry, mechanical properties and microstructural behavior were recorded. The average voltage used for welding in Ar gas protection was higher than for $\mathrm{N}_{2}$, while the current during short circuiting transfer was reported to be lower for nitrogen. The average microhardness value was seen to be higher when using $\mathrm{N}_{2}$ as shielded gas, but generated an anisotropy in material. The use of argon determined a higher UTS and elongation, while the yield strength was higher when using nitrogen. Because of the presence of flaky nitrides, generated by the reaction of N2 with $\mathrm{Al}$, a decrease of strength and plasticity was noticed, while in the case of using $\mathrm{Ar}$, which does not react with $\mathrm{Al}$, the properties were not affected. $\mathrm{N}_{2}$, as shielding gas, triggers a desirable large height to width ratio, limited penetration, roughness in the weld beads and smaller grain size. The smaller weld penetration was attributed to the heat absorption, breaking and further ionizing of the N-N bond causing temperature decrease. The roughness was attributed to poor stability of the droplet transfer. Yang et al. [29] proposed a double electrode gas metal arc welding (DE-GMAW) for the fabrication of narrow thin wall metal components with high deposition rate and efficiency in comparison to conventional GMAW (Figure 12). For the same deposition rate, the width of the deposited layer was noticed to be directly proportional, while the layer height is inversely proportional to the bypass current.

The studies presented in this section provides significant information, useful for choosing the appropriate WAAM heat source employed for specific applications. The selection criteria are based on the key factors described in the following comparative analysis.

GMAW based WAAM provides various modes of metal transfer, starting with the globular transfer, short-circuiting, spray, and ending with the pulsed-spray transfer. The stability of the electric arc is poor in this process, but the average rate of deposition is about $3-4 \mathrm{~kg} / \mathrm{h}$. The high deposition rate makes this process a suitable choice for the large-scale industry. 
CMT based WAAM is characterized by better electric arc stability and higher quality deposition of material, but the average rate of deposition is more reduced $(2-3 \mathrm{~kg} / \mathrm{h}$ ). Applying this process, the heat input is significantly lower, the distortion is reduced, and the material spatter is eliminated. Based on these features, this method could be a good choice in fabricating thin-walled components.

Plasma based WAAM is a process that uses separate feeding wires, but the fabrication cost is more expensive compared to the methods mentioned above. The average deposition rate is about $2-4 \mathrm{~kg} / \mathrm{h}$ and it is recommended for producing width-walled structures with negligible spatter.

Laser-based AM is characterized by good performances, such as high precision, deposit quality, and appropriate morphology. The average deposition rate is around $10-12 \mathrm{~kg} / \mathrm{h}$ that makes this method to be a high efficiency process.

Electron beam (EB) assisted AM process can be employed for a large range of metals, including highly reflective alloys, such as copper and aluminum. The average deposition rate achieved during the process is up to $10-14 \mathrm{~kg} / \mathrm{h}$. Even if it is a fast-manufacturing method, the process is carried out in a high-vacuum chamber that limits the size of the parts to be printed.

Various modes of arc generation and transfer, i.e., pulsed/non-pulsed arc or droplet/bridge transfer, result in variation of the WAAM builds. The use of different shielding has also an effect on the tensile properties of the builds. The appropriate selection of heat input systems and shielding gases plays a significant role in the design of the WAAM techniques for specific applications.

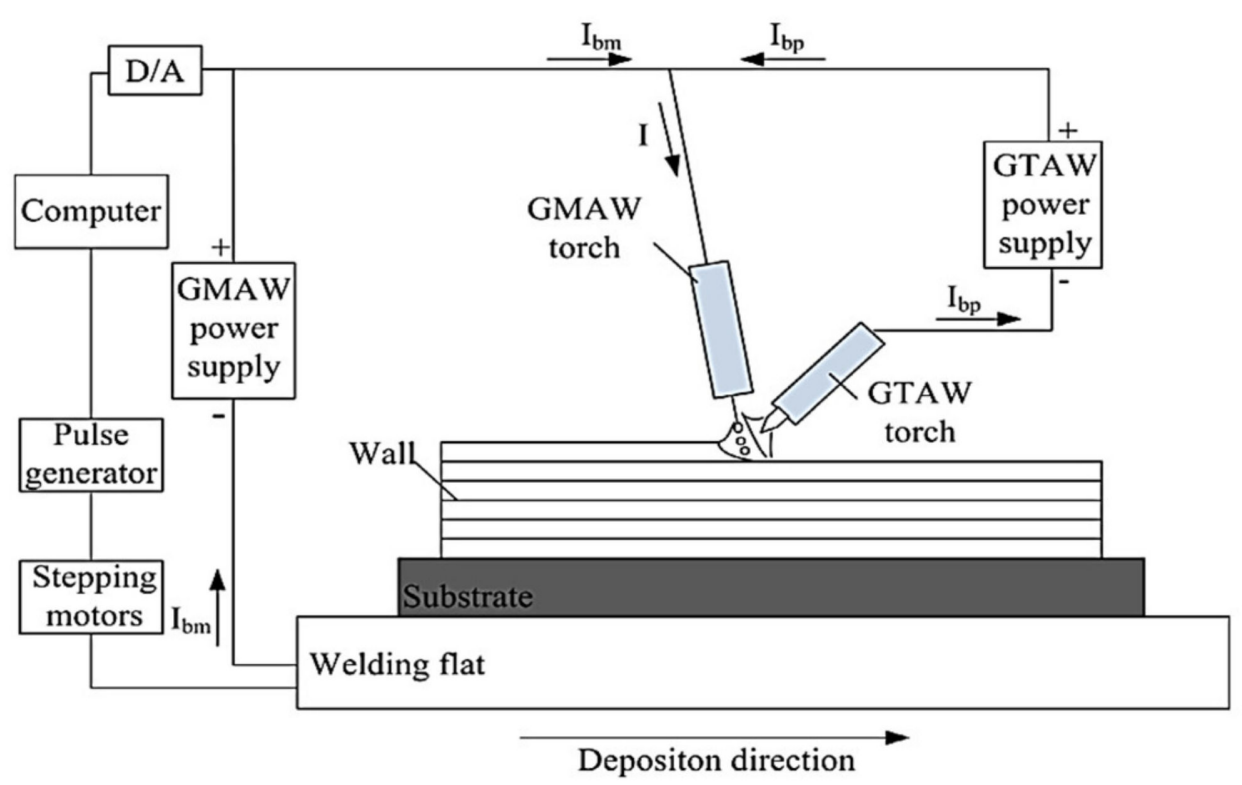

Figure 12. Schematic of double electrode GMAW based WAAM system. Reprinted with permission from Ref. [29]. Copyright 2016 Elsevier.

\subsection{Process Monitoring and Control for Optimizing the WAAM}

WAAM, being an autonomous system, is governed by its monitoring and control modules. This section covers the research works carried out in the related domain. Efficient WAAM builds can be manufactured with precise control of the process parameters, with different configurations of heat input or by controlling the thermal gradients in the process. To achieve quality samples, careful control of the WAAM process parameters and various combinations are needed [30-35]. 
Mok et al. [30] reported that front and side feeding provided a smoother surface, as compared to back feeding, and a proportional relation between the deposition rate and the wire feed rate was noticed. Traverse speed influences the deposit height more than laser power. If the angle of inclination is maintained $31-68^{\circ}$, then a dense deposition with negligible porosity is achieved. The deposits exhibit a columnar structure, and the cooling direction has a great influence on the grain structure.

Dinovitzer et al. [31] analyzed the effects of the process parameters on the TIG based WAAM product of HastelloyX alloy and 304 SS plate. They noticed that the melting depth and the roughness depend on the current and are independent of wire feed rate and bead width. The travel speed has a proportional influence on the bead height, but a converse one on the bead width. Molybdenum carbide structures formed were influenced by the thermal gradient and deposition rate.

Wahsh et al. [32] utilized Robot's synergic operations for optimized large-scale production of Al walls using CMT-P WAAM process with constant heat input and predetermined current. The meso-structure revealed minimized spherical gas porosity in the build direction for low heat input in CMT-P mode. This also minimized the diffusivity of hydrogen into aluminum. The decreased rate of heat dissipation and the preheating led to thermal balance, causing solidification of dendritic grains. Kumar et al. [33] employed Taguchi method for optimization of welding speed, wire feed speed and voltage for a specific weld geometry. Weld bead width was proportional to the voltage and wire feed speed and inversely proportional to the welding speed. The welding speed is altered by increasing the heat input, while the variation in arc length affects the voltage. Su et al. [34] pointed out an increase in the effective wall width of Al-Mg products with an increase in wire feed speed (WFS) and decrease in tool speed. The increase in tool speed promotes the $\mathrm{Al}$ (111) orientation and the wire feed speed opposes the $\mathrm{Al}$ (200) peaks. Modifying the tool speed and the wire feed speed, the texture of the samples during the deposition process is consequently altered.

Zhou et al. [35] concluded that an increase in tool speed has no implications on the heat input per unit time, but reduces the energy obtained per unit area, causing a decrease of the samples' width and height. Low tool speed caused more weld ripples, while high tool speed increased the solidification rate and, consequently, the grain size was smaller with refined dendrite formation. However, the tensile properties improved with the tool speed up to a certain value, beyond which it declined owing to the increasing the electric field.

Researchers are constantly involved in innovative designs and the development of monitoring and control mechanisms [36-38] in order to maintain the distance unchanged between nozzle and surface, between layers, or to monitor the thermal gradients, so that the process parameters applied are optimal to build certain structures with the required characteristics.

Xiong et al. [36] developed a passive vision control system of the GMAW-AM process, meant to monitor the nozzle to the deposition surface distance. The authors also designed an adaptive control system to maintain constant the distance and they obtained results with a precision range of $\pm 0.5 \mathrm{~mm}$.

To monitor the process, Artaza et al. [37] proposed the use of a five-axis gantry machine and a height adaptive control mechanism for the complex parts fabrication. The height adaptive control required enabling communication protocols between the PC, gantry machine, laser scanner, and the plasma control. This allows for the manufacturing of identical parts in a controlled environment.

Anikin et al. [38] proposed a software and hardware architecture for robotic control system of the WAAM process (Figure 13) that includes thermal feedback devices. The CNC system is designed to control the motion system (determining speed and trajectory), the power source (switching on/off, amperage, impulse, arc length, wire feed-speed), the pattern, and the shielding gas system. 


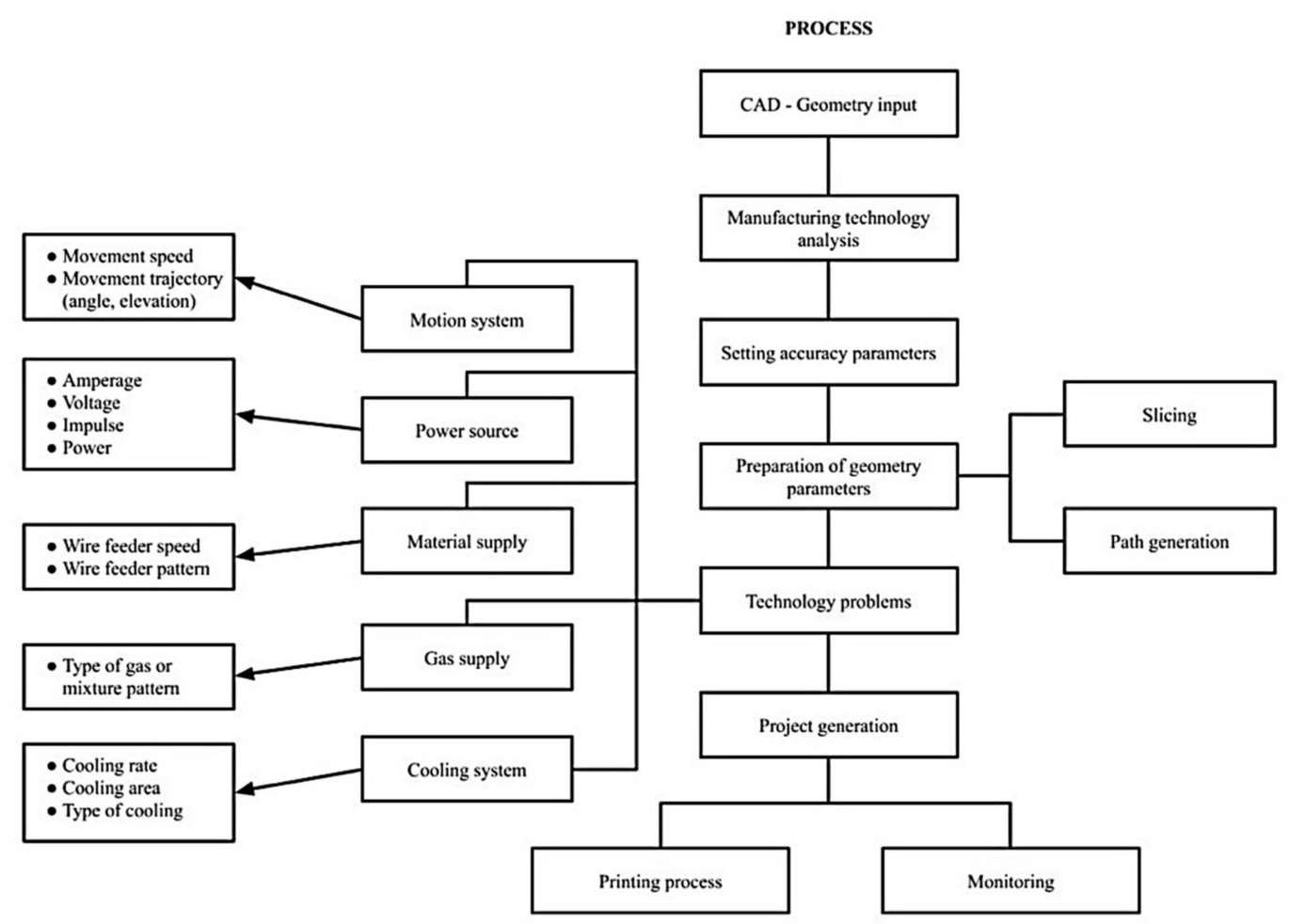

Figure 13. Software and hardware architecture for robotic control system of the WAAM. Reprinted from Ref. [38].

Silva et al. [39] proposed AM with plasma welding by developing a controlled mechanical welding torch holder to generate the required pulsed arc velocity and maintain the optimum position on the displacement axis for continuity and controlled height variation or defects in the weld. The supply frequency and operating voltage may be controlled for deposition rate adjustment. Differential thermal gradients, determined by repeated heating and cooling, are seen to be the major cause for the generation of residual stresses and distortion. Various mechanisms have been investigated [40-42] on preheating, control that governs the thermal gradient or the interpass temperature or the arc energy. The temperature field reduces the residual stresses in WAAM builds. Xiong et al. [40] explored substrate preheating to minimize the temperature gradient as a solution to reduce the cracking and thermal stress in GMAW based AM products. The reduced thermal gradient in turn reduces the deposition height.

Radel et al. [41] proposed an auto-controlled system using six-axis robot for producing complex truss structures. They also designed computer aided manufacturing (CAM) software for avoiding the torch-structure collision and to control the intersection of material depositions. The correction of the geometry for the following deposition was enabled by video imaging of the bead deposition contour.

Ali et al. [42] studied the impact of the arc energy and of the temperature field on the mechanical properties of the hot work tool steel structures. They employed a fourroll drive system for feeding the welding wire. It was noticed that if the temperature is maintained above the martensite start temperature, then uniform hardness is achieved along the structure height.

Derekar et al. [43] investigated the DC pulsed GMAW process on the Al5356 alloy and reported that the formation of large pores is a function of solubility limit, temperature and heat dissipation rate. Rate of heat extraction facilitates the movement of entrapped dissolved hydrogen through the pipes. Different solidification rates cause hydrogen entrapment of varying intensity, with a higher interpass temperature in horizontal specimens that led to a reduction in the size of pores while the strength increased. Ortega et al. [44] focused on the formation of defect-free multilayer thin metallic walls with CMT for Al5Si. 
Irregular product dimensions could be avoided with constant deposit rate and increasing the travel speed.

Ryan et al. [45] examined the AA2319 WAAM panels on the batch variability of wires and reported that the surface finish of the wires affects the hydrogen content and the arc stability. Hydrogen entrapment led to the spherical pore formation caused by the shrinkage during solidification.

Quality improvement in WAAM products requires optimization of process parameters and the torch tool path to obtain near-perfect bead geometry. To address the optimization issues, a variety of factors such as the wire feed speed, tool speed, the effect of inter-pass temperature, the dependency of hardness on heat input for specific materials, the formation of intracrystalline precipitates and their influence on the build properties have been taken into consideration. Complete understanding of the dependency of build properties on the process parameters will generate reduced defects, surface irregularities, and residual stresses. Studies focused on in-situ monitoring, control and testing have been performed by researchers, as they bring about appropriate build properties with reduced wastage and production times. Several strategies have been proposed to optimize the microstructure and mechanical properties, which are based upon required testing, and can be adapted as standard practices for acceptance in the industry.

During the deposition process, as the number of the deposited layers increases, the control of the deposited layer size, as well as the morphology that governs the geometrical accuracy, seems to be a complicated task. When the melt pool is close to the boundaries of the layer deposited, the control of the bead shape would be intricate due to the heat accumulation. Hence, the loop feedback control of the WAAM process is vital in making reliable products by this technique.

Several control algorithms, such as fuzzy control, predictive control, iterative learning control, proportional-integral-derivative (PID), fuzzy-PID, inverse ANFIS model-based control, and adaptive control, have been developed for controlling and monitoring the WAAM process. The adaptive controller is observed to be effective for the layer height adjustment, due to maintaining constant the distance between the nozzle and the top surface (NTSD). Moreover, the adaptive process control is useful for maintaining the uniformity of the bead geometry. Based on the dynamic constraint, the optimal/suitable wire-feed rates are dynamically selected by this method. Other controllers, mentioned in this section, have been developed for the control of layer height, temperature and width of the melt pool. Nevertheless, the dynamic self-assessment and control are quite ineffective, because the time constant is high and reasonable results are mostly yielded only for the linear parametric variations.

The mathematical model accuracy may not be significant for Fuzzy logic-based controller, but needs wider knowledge and experience to be implemented. It is obvious that the PID parameters need to be customized to function adaptively, and to accommodate time varying system with the fuzzy logic support. These adaptive control models facilitate the development of relationships between the temperature, and traverse speed, melt rate, deposition rate and layer height. It may conclude that the implementation of the mechanism-based adaptive control would provide a breakthrough for new WAAM versatile applications in industry.

\section{Discussion on Materials Behavior during WAAM}

This section presents the behavioral aspects expressed in terms of the variations of the WAAM process parameters. This includes heat source, processing conditions, wire feed, rolling, heating mechanisms, and other enhancements deployed to optimize the manufacturing process. Various research groups are working on different materials to understand the technical challenges when the materials are subjected to WAAM process. This section provides valuable information in terms of perspectives, applications of advanced tools, interpretations, and standards specific to the materials approached. 


\subsection{Ti-6Al-4V Alloy}

Ti-6Al-4V has been a popular choice for a number of industrial applications owing to its suitability in the aerospace industry, which is oriented towards more enhancements for optimum performance. WAAM with laser as energy source was experimented [46] and it was found that the globular grain size and column grain width are proportional to laser beam power and wire feed speed, but inversely proportional to weld speed, while the epitaxially grown columnar resulting from nucleation in the microstructure has larger width. Increased weld speed also caused constriction due to rapid solidification. The mechanical properties showed an anisotropic trend, while the characterization of horizontal builds revealed a higher fatigue strength and ultimate tensile strength (UTS) with lower ductility, compared to the wrought materials. The microstructures revealed an anisotropy with columnar grain structure in alignment with the build direction. The microstructural transformations showed coarsening of grains and the gradual formation of a fine equiaxed structure with nucleation that results in epitaxial grain growth.

When the PLASMA source is used as a technique of reversed deposition, a high deposition rate and efficiency, as well as an increase of UTS by $12 \%$ and a wider wall width have been obtained. Banding was recorded with an increase in alpha lamellar size between the bands. The enhancement of PLASMA source WAAM, i.e., continuous plasma WAAM with high energy density, was analyzed [17] by reducing the heat input layer by layer. The energy accumulation in the molten pool is diminished and that allows for an easy nucleation, prevents the air oxidation phenomenon and the development of multiple thermal cycles. Equiaxed rectangular grid, representing martensite, new alpha plates, representing basket weave structure, and formation of horizontal bands determined by thermal cycle were also highlighted. These bands show low hardness with formation of alpha colonies.

Due to the impact on the cooling rate, by reducing it, and, further, reflected in high heat fluxes at higher temperature, the variation of interpass temperature during WAAM [47] needed studying. Though the hardness value reduces up to the interpass temperature, it results in finer and lesser dendrites and interdendritic areas in top portions compared to the middle, thus showing anisotropy. In the latest research studies [48], the WAAM process was modified by adding $\mathrm{N}_{2}$ along with the shielding gas, which led to the modification of the arc shape and to the hardening of TiN layer deposition over the Ti6Al4V substrate called surface cladding. The friction coefficient and wear resistant property were improved with the $\mathrm{N}_{2}$ addition in the shielding gas. The resulting TiN phases showed coarse dendrites and irregularities caused by the moisture on the cladding layers. The mechanical properties, on the contrary, improve and the microhardness increases with increasing the $\mathrm{N}_{2}$ flow rate. Another study of the WAAM process [49] revealed that an increased dwell time resulted in an increased yield strength and hardness and reduced width of alpha lath in the layer band region. Microstructures showed equiaxed beta grains and tilted layer band due to bidirectional travel mode. Ti-Al alloys were subjected to dual-wire arc AM [50], the wire feed rate being controlled to obtain different phase compositions (Ti-45Al and Ti-55Al) and microstructures. Microhardness, yield strength (YS) and ultimate tensile strength (UTS) were seen to decrease with the increase in Al content, while the elongation was not consistently affected. As regards the microstructure, the modification of the Al percentage promoted the development of gamma dendritic structures with four-fold symmetry.

\subsection{Aluminum Alloys}

Geng et al. [51] explored the geometric limitations and tensile characteristics by investigating the WAAM of 5A06 Aluminum Alloy with $1.2 \mathrm{~mm}$ thickness. It was noticed that the tensile properties are obviously influenced by the build direction and the texture orientation, showing isotropy in the build direction, but anisotropy with respect to the texture orientation. Because of the weld bead overlapping that may occur owing to the large molten pool and to the effect of surface tension, WAAM with a layer width of $7.2 \mathrm{~mm}$ cannot be applied for plane shapes with certain geometrical features, such as 
sharp angles less than $20^{\circ}$ or curvatures greater than $10 \mathrm{~mm}$. In the case of axial loading, acting perpendicular to the texture orientation, a large number of grain boundaries become resistant to deformation, while on parallel loading to texture orientation, a sliding of grain boundary occurred in the bounding region, determining the tensile strength decrease.

Horgar et al. [52] studied the feasibility of WAAM for $1.2 \mathrm{~mm}$ diameter AA5183 alloy used as wire and AA6082-T6 plates of $20 \mathrm{~mm}$ thickness as base material. It was noticed that the tensile and hardness properties were anisotropic with the plane orientation and the deposition direction. The macro inspection of the weld showed intergranular hot cracks in the high temperature part of the reheated area with equiaxed grains. The dilution of AA5183 with AA6082 generates the formation of hot cracking, which can be reduced with addition of $\mathrm{Ti}, \mathrm{B}, \mathrm{Sc}, \mathrm{Er}$, or $\mathrm{Zr}$ in the composition of the wire material. Due to the grain refinement effect of nanoparticles, the additives have a positive effect on the tensile and ductile properties and minimize the cracking tend.

Qi et al. [53] developed the double-wire plasma system for WAAM of Al-6.3Cu alloy and added $\mathrm{Mg}$ into $\mathrm{Al}-\mathrm{Cu}$ alloy with the aim of improving the mechanical properties. The amount of $\mathrm{Cu}$ and $\mathrm{Mg}$ was adjusted with the wire feed speed. The tensile strength and elongation were noticed to be isotropic in both directions. The microstructure showed a non-uniform distribution of coarse columnar and fine equiaxed grains in the inner layer, while the inter-layer region had equiaxed grains, as illustrated in Figure 14.

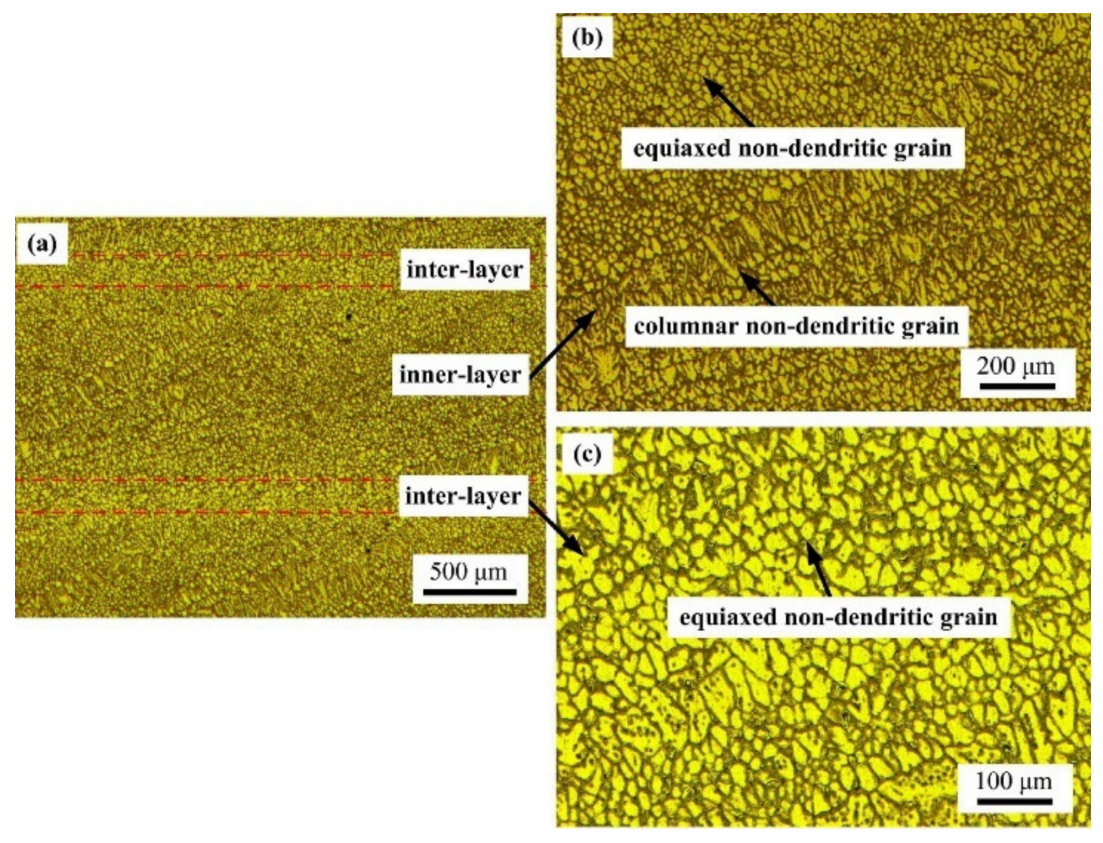

Figure 14. Optical microscopic images of WAAM Al-Cu-Mg alloy: (a) Al-3.6Cu-2.2Mg, (b) inner-layer of Al-3.6Cu-2.2Mg, (c) inter-layer of Al-3.6Cu-2.2Mg. Reprinted from Ref. [53].

Gu et al. [54] proposed the hybrid technique of WAAM, incorporating the rolling and heat treatment, to control the porosity and to optimize the process parameters. They noticed that, by increasing the interlayer rolling loads, the tensile properties of the WAAM alloy were improved, while the elongation was altered. During the heat treatment, the samples were exposed to homogenization temperature and then to cold water quenching to enable micro segregation. After the heat treatment, the vacant voids generated an increased number of irregular micropores.

$\mathrm{Li}$ et al. [55] reported a growth of the secondary dendrite arm spacing and of the Fephase when the heat input, generated by the WAAM with CMT process for Al-7Si-0.6Mg, increased. The increase of the heat input, with corresponding decrease in welding speed, has determined an increase of thickness and layer height, as well as an increase of the size of primary alpha-Al grain size and eutectic Al-Si grains. As regards the mechanical 
properties, such as UTS, YS, and elongation, it was pointed out that the heat input has a crucial role in modifying them.

Qi et al. [56] investigated the double-wire WAAM process, the AA2024 samples being subjected to heat treatment with the aim of overcoming the restrictions of building the components with single-wire WAAM. The T4 and T6 heat treatments involve solution heat treatment, followed by natural and artificial aging respectively, to attain a substantial stable condition. After heat treatment, the microstructural analysis revealed that the dendrite morphology changed from $\alpha-\mathrm{Al}+\mathrm{Al} 2 \mathrm{Cu}+\mathrm{Al} 2 \mathrm{CuMg}$ to $\alpha-\mathrm{Al}+\mathrm{Al} 2 \mathrm{Cu}$. The solid wires ER2319 (Al-6.3Cu) and ER5087 (Al-5Mg) of $1.2 \mathrm{~mm}$ diameter were used as filler materials in the WAAM of AA2024 plate of $12 \mathrm{~mm}$ thickness. It was found that the microhardness significantly increased after the T4 and T6 heat treatment process. Heat treatment determined a strength increase, while the elongation increased in horizontal direction and diminished in vertical direction and, consequently, an improvement of tensile properties in the horizontal direction has been achieved. Intergranular and trans-granular fractures with some dimples were pre-dominantly noticed (Figure 15).
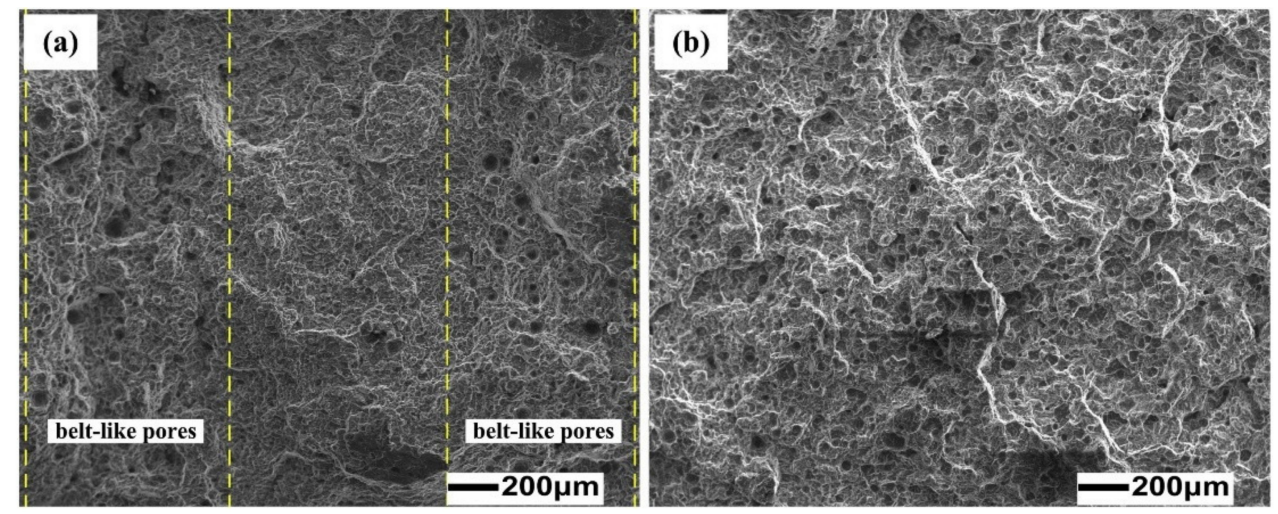

Figure 15. Fracture morphology for WAAM 2024 alloy in T4 condition: (a) horizontal direction; (b) vertical direction. Reprinted from Ref. [56].

Ünsal et al. [57] used the alloy EN AW 6016, as the wire for WAAM, to manufacture bulk material with less than $1 \%$ porosity and no lack of fusion. The hardness of the asbuild sample was not comparable to the conventional material due to high temperature impact. The heat-treated material shows hardness comparable to or even larger than the conventional material. During the initial layer deposition, heat input was controlled with high amperage (110-140 A). For higher layer depositions, weld velocity was varied to control the heat input.

Wang et al. [58] investigated the WAAM of Al-Cu-Sn alloy and noticed that by increasing the heat input, the molten pool widens, the grain size grows and defects such as pores are developed in the deposited material. The porosity phenomenon is related to the increase of hydrogen solubility in $\mathrm{Al}$ solution with temperature and to the faster nucleation of pores determined by the larger heat input. The uniformity of grains decreased with temperature and the number and the size of undissolved $\theta$ phases increase after the solution treatment, altering the mechanical properties.

Yang et al. [59] studied the CMT-based WAAM for manufacturing the AZ31 walls and they reported an enhancement of tensile properties in the metal deposition direction. The microstructural analysis revealed vertical dendrites and alignment of changed columnar dendrites in sequence as well as equiaxed grains in the top layer. The thin-walled deposit comprises of columnar dendritic arrays, including alpha $\mathrm{Mg}$ matrix, inter-dendritic eutectics, and some dispersive $\mathrm{Al}-\mathrm{Mg}$ phases. The tensile properties depend on the solidification direction of dendrites and on the volume fraction of the inter-dendritic eutectic. Due to the growth of epitaxial columnar dendrites, an anisotropy has been noticed in the deposit direction. 


\subsection{Chromium}

Ge et al. [60] investigated the WAAM process of $2 \mathrm{Cr} 13$ parts and noticed that the CMT-based WAAM process develops a stable liquid metal transfer, as indicated in the build structure (Figure 16a). The microstructure, presented in Figure 16b, reveals no-austenite formation and defects between adjacent layers. The top layer is characterized by elongated ferrite grains, as reported in [60] (Figure 16c). The microstructures consisted of thermally decomposed martensite and block shaped ferrite caused by repeated heating-cooling cycles. Besides, the ferrite content decreased towards the base metal due to the microstructure variation noticed in the middle zone of the metal deposit (Figure 16d).

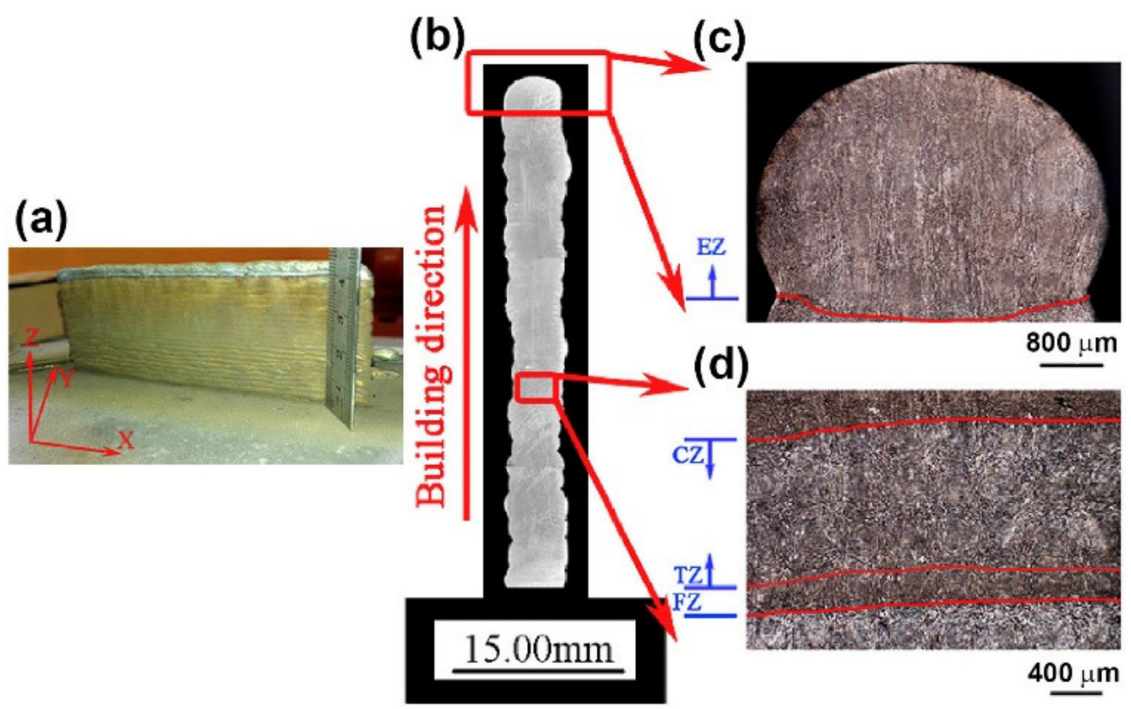

Figure 16. WAAM process of $2 \mathrm{Cr} 13$ alloy: (a) macroscopic morphology; (b) cross section; (c) top zone; (d) middle zone. Reprinted from Ref. [60].

High UTS and reduced ductility were noticed in the WAAM samples due to higher dislocations density and finer martensite laths, resulting in dislocation pile-up at grain boundaries during the mechanical testing.

\subsection{Inconel}

$\mathrm{Xu}$ et al. [61] studied the microstructure and aging response of Inconel 718 alloy determined by the WAAM processes for IN718. The strength of the weld was found to be lower than the strength of the forged material. They proposed the use of inter-pass rolling with the aim of improving the mechanical properties. The thermomechanical processing serves to enhance the strength and reduce the material anisotropy and the aging response generated by the WAAM process. The macrostructure of the sample, which was subjected to inter-pass rolling, exhibits smaller columnar grains aligned to the wall sides and duplex grain structure with re-crystallized core that extends up to half the wall thickness (Figure 17).

As Figure 18 shows, the microstructure of the rolled sample achieved after solution plus aging treatment presents fewer dendrite structures grown in random directions, in comparison with the unrolled sample, that determines the improvement of tensile, elongation, and ductility properties.

Seow et al. [62] investigated the issues generated by the WAAM deposition process in the IN718 material, such as micro-segregation, that caused undesirable Laves-phase formation in the inter-dendritic regions, and proposed a modified heat treatment. This method aims at dissolving the Laves-phase and at reducing the anisotropy in the grain structure, achieving isotropic tensile properties at high temperature. The heat treatment phases consist of homogenization at $1100^{\circ} \mathrm{C}$ for $1 \mathrm{~h}$, air cooling, and then solution treatment at $980{ }^{\circ} \mathrm{C}$ for $1 \mathrm{~h}$ followed by air cooling, according to AMS 5383 and modified homogenization treatment at $1186^{\circ} \mathrm{C}$ for $40 \mathrm{~min}$, air cooling. 


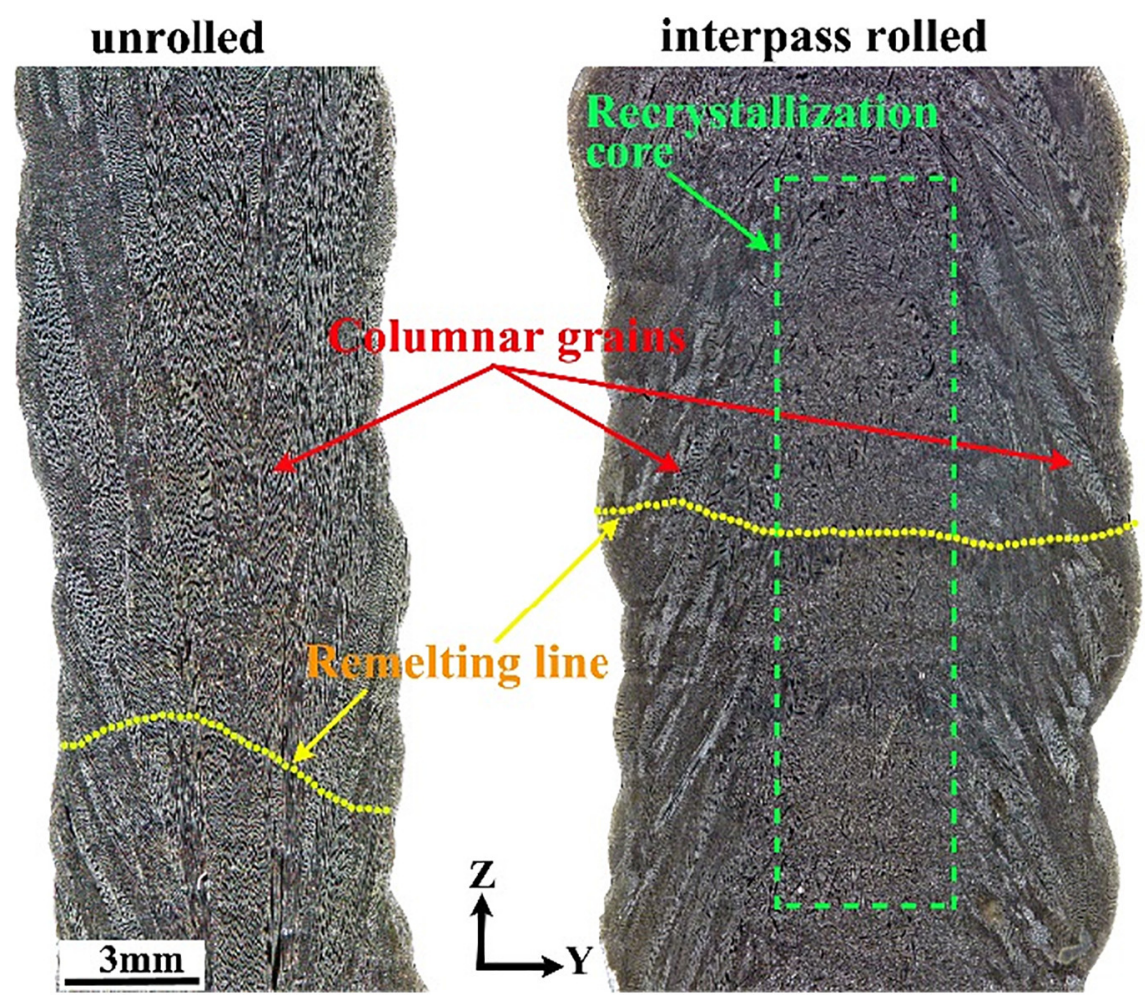

Figure 17. Macrostructure of unrolled and rolled samples. Reprinted from Ref. [61].

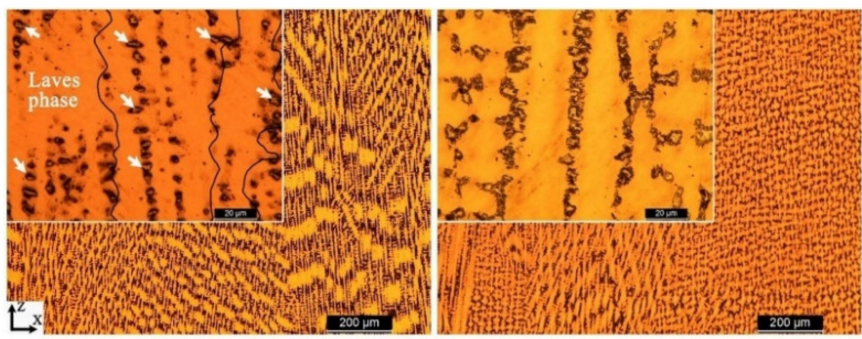

(a)
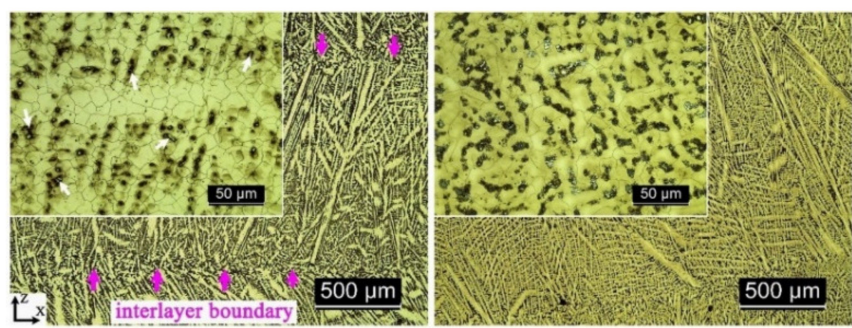

(b)

Figure 18. Microstructure of IN718 through WAAM: (a) unrolled; (b) rolled. Reprinted from Ref. [61].

The high temperature treatment enables the dissolution of Laves-phase by diffusion into the matrix. This dissolution could develop $\mathrm{Nb}$-enriched regions where delta phase may precipitate. Because of the precipitation of gamma particles in the matrix, promoted by the aging treatment, the hardening effect could be enhanced. On the other hand, the development of coarsened grains determines lower hardness and tensile properties in the samples subjected to the modified heat treatment proposed [62].

Yangfan et al. [63] investigated the effects of the torch travel speed on the microstructure and mechanical properties of the Inconel 625 alloy deposited by a CMT-based WAAM technique. The analysis revealed a modification of the microstructure in different layers. 
The deposition direction was reversed after each layer and this resulted in a well-defined bead and layer interface, Figure 19.

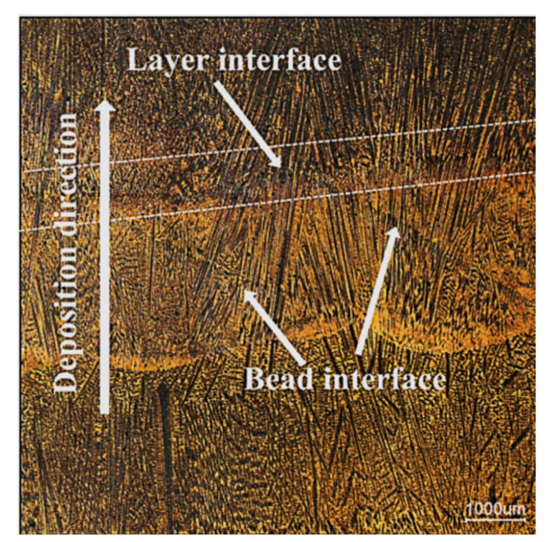

Figure 19. Microstructure in the interlayer of sample. Reprinted from Ref. [63].

Due to the slower heat dissipation in the middle region, a cellular dendritic structure with some secondary dendrite was developed, while a coarser dendritic structure was generated in the top region because of the continuous accumulation of heat in this area. Thus, the microstructure achieved is finer and the microhardness increases with increasing torch travel speed. Consequently, the yield strength (YS), ultimate tensile strength (UTS), and the elongation of the manufactured samples gradually increased as the torch speed increased.

\subsection{Tungsten}

Tungsten is a high-performance component and finds application in nuclear fusion reactors and other high temperature energy generation and conversion systems. Some of the physical characteristics, such as high recrystallization temperature and low fracture toughness, raise difficulties in the conventional manufacturing of tungsten components. WAAM process modularity and configurable process parameters and ability to produce functionally graded elements enable the development of required features in Tungsten structures. Marinelli et al. [64] studied the influence of WAAM process parameters on the linear structures of unalloyed tungsten. A precise substrate orientation and an appropriate clamping system design led to the elimination of lateral cracks that can be developed during the deposition process. In comparison to the front wire feeding mechanism, the side wire feeding has created splatter, voids, cracks, and a lack of fusion, as shown in Figure 20.

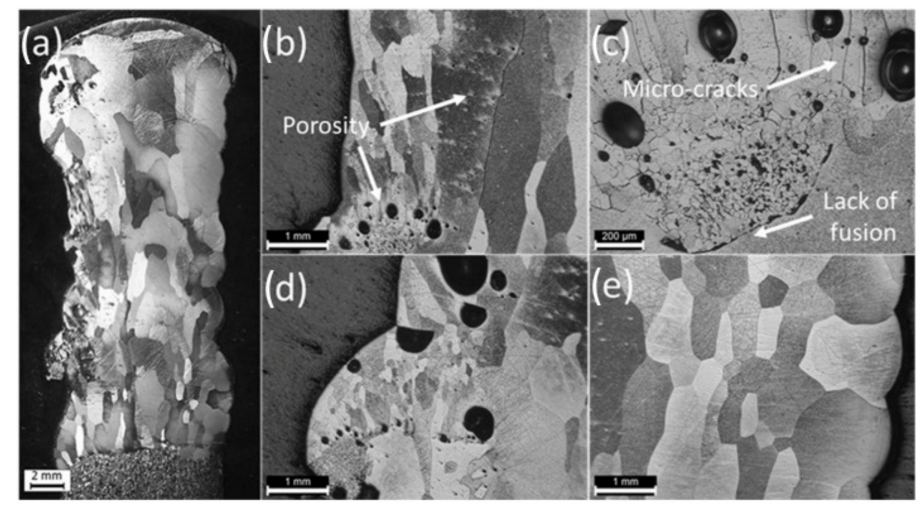

Figure 20. WAAM process parameters on the linear structures of unalloyed tungsten: (a) microstructure defects using side wire feed; $(\mathbf{b}-\mathbf{d})$ details of the defects located on the side facing the wire feeder; (e) detail of the microstructure at the base of the linear structure. Reprinted with permission from Ref. [64]. Copyright 2019 Elsevier. 
Kelvin-Helmholtz instability was noticed in the side wire deposition process due to the difference between the densities of liquid tungsten and helium plasma that causes the breakup of melted surfaces and the splitting of particles in fine droplets. The fast solidification and the relatively high thermal conductivity of Tungsten led to development of equiaxed grains. The upper part of the structure had large and elongated grains because thermal conductivity decreased at high temperatures.

\subsection{Tantalum}

Marinelli et al. [65] developed large-scale unalloyed Tantalum parts using WAAM with two different Ta wires and highlighted that the deposited walls have high geometrical stiffness and no distortion.

Conventional TIG technique was employed for Ta deposition in a single bead. The unidirectional deposition was maintained at each layer with side wire feed to the weld pool. The wall structure had no distortions due to high geometrical stiffness and a localized plastic deformation at the substrate-wall interface. The microstructure analysis revealed that the columnar grains grew epitaxially in the deposition direction during solidification (Figure 21).

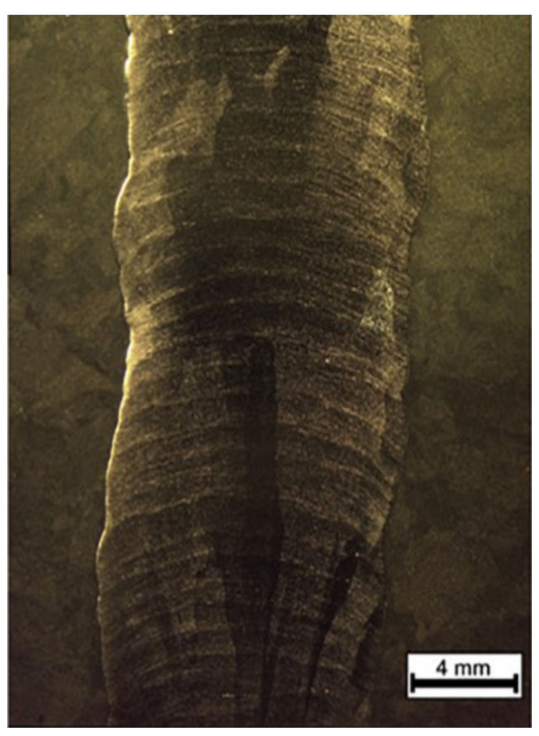

Figure 21. Microstructure showing epitaxial growth of columnar grains in build direction. Reprinted with permission from Ref. [65]. Copyright 2019 Elsevier.

Due to repeated heating cycles that further caused localized change of $\alpha$-grains in successive layers, the development of macroscopic banding was noticed in each layer. However, for the unalloyed Ta, sub-grain structures did not develop in the reheating process of successive layers and the bands could be attributed to the regular dispersion of Ta oxide particles. The hardness analysis revealed a variation in the build direction because of the thermal cycles which induced the hardening effect on the lower part of the build. It was found that the deposited structures were characterized by higher yield strength due to oxygen content and by reduced elongation caused by different grains size and shape between substrate and samples. In comparison with other manufacturing techniques, this manufacturing method has the advantage of reduced cost and time to produce large scale Ta structures.

\subsection{Copper}

Wang et al. [66] studied the CMT-based WAAM of $10 \mathrm{~mm}$ thick copper plate with wires containing $\mathrm{Cu}$ or $\mathrm{Al}$ and $\mathrm{Si}(\mathrm{CuSi} 3, \mathrm{AlSi} 5-\mathrm{ER} 4043)$. The experiment setup included a wire feeder machine feeding the two wires into a single molten pool. The percentage of components deposited on the $10 \mathrm{~mm}$ copper plate is controlled by the variation of the wire 
feed rate. It was noticed that the addition of Si enables the uniform metal intermixing and the reduction of intermetallic phases formation.

Due to solid solubility with $\mathrm{Cu}$ and $\mathrm{Al}$, Si increases the fluidity of the molten metal. $\mathrm{Al}$ was maintained at 4.3. It was noticed that, increasing the $\mathrm{Al}$ content, an increase of the UTS and YS properties was achieved, while adding $\mathrm{Si}$ to $\mathrm{Cu}-\mathrm{Al}$ alloy, an improvement of hardness, tensile strength and offset yield strength was obtained. Frequent heating-cooling cycles and the thermal stresses cause poor bonding between the base deposited layer and the substrate. The stabilized thermal gradient controls the wall width increase in the build direction. The layer height was noticed to diminish in the build direction. Besides, the increased hardness is caused by the solid solution strengthening effect of $\mathrm{Al}$, by the formation of intermetallic phases, and by $\mathrm{Si}$ addition.

The interlayer structure showed a mixed and disordered structure where twinned, coarse columnar and fine lamellar crystals coexist. The effect of oxidation is visible in the form of black columnar crystals in microstructure, as Figure 22 shows. Modifying the heat dissipation rates, a different morphology of deposited layers is obtained in the build direction and across the structure.

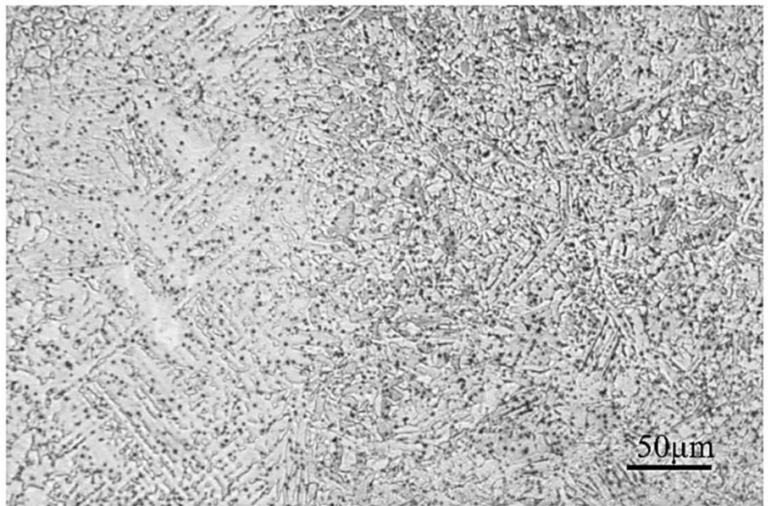

(a)

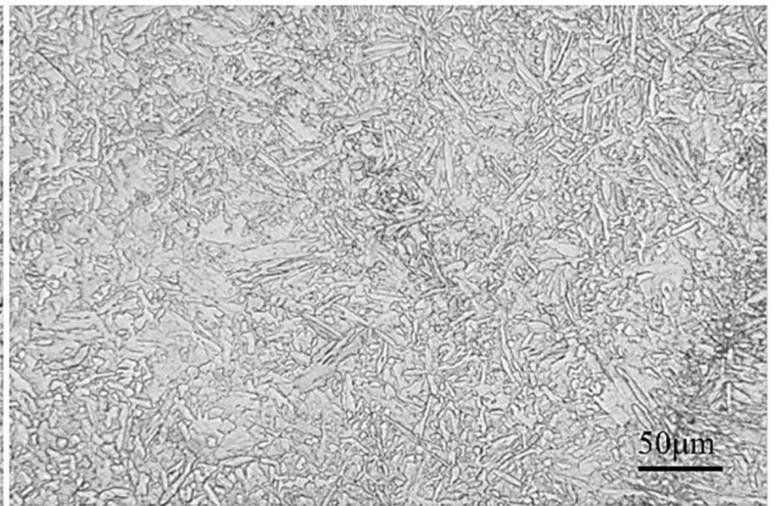

(b)

Figure 22. Microstructure of sample: (a) bottom section; (b) middle section. Reprinted from Ref. [66].

\subsection{Steel Alloys}

Though the paper focuses on the characterization of non-ferrous behavior during the WAAM process, the technique is widely adopted for steel alloys, too. However, the discussion on this type of alloys may give insights into the research possibilities that could be extended to other non-ferrous materials.

Haden et al. [67] studied the mechanical properties of the SS304 and ER70S components achieved by WAAM. In the case of SS304, the yield and tensile strength were found to be isotropic along the direction of deposition. Similarly, for the ER70S mild steel, the anisotropy was observed in the vertical and horizontal directions. A grain refinement was also noticed in the SS build, as Hall-Petch strengthening under the wear scars. The YS increased both in the direction of the weld deposition and in the $\mathrm{Z}$ direction. The microstructure of SS304 showed a variation from the austenitic to mixed ferrite morphology, due to the influence of local thermal gradients (Figure 23). As regards the ER-70S, it exhibited a typical ferrite microstructure with small regions of pearlite at grain boundaries (Figure 24). 


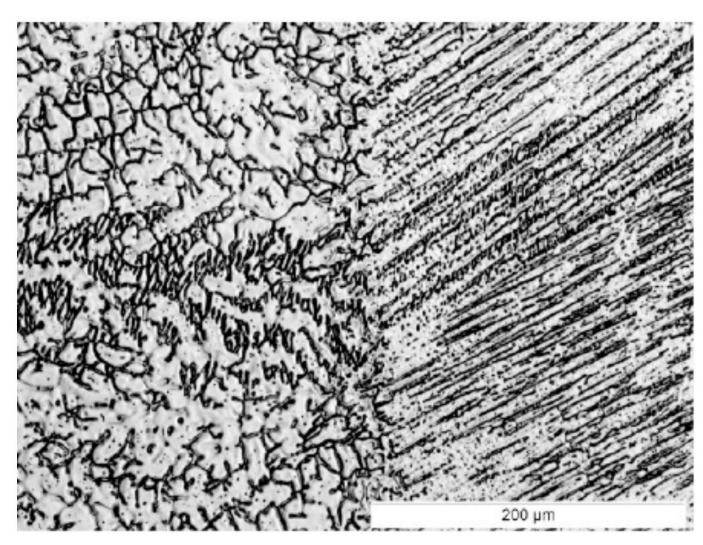

Figure 23. Microstructural shifts in SS304. Reprinted from Ref. [67].

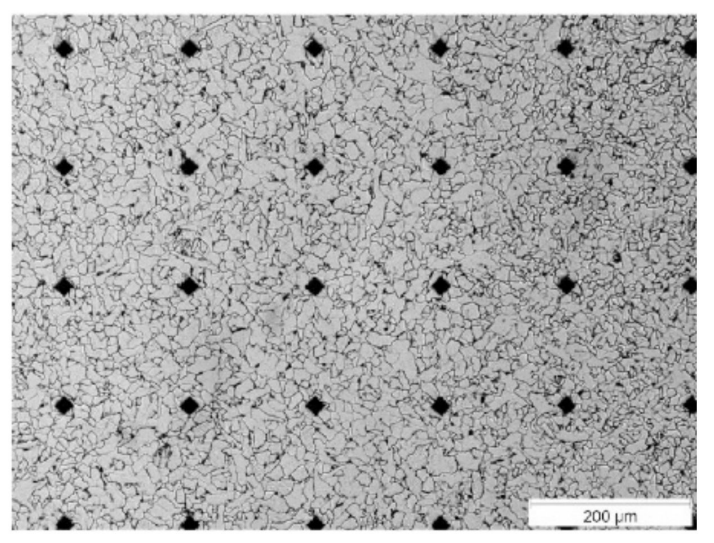

Figure 24. ER70S: Ferrite microstructure with small regions of perlite at the grain boundaries. Reprinted from Ref. [67].

Feng et al. [68] observed an improvement in terms of bead appearance, deposit rate, microstructures and mechanical properties of the weld when the manufacturing process is plasma induced arc-based WAAM process with double wire feeding. The macroscopic analysis, performed on different samples, showed a diminution of deposited wall's height, surface forming and waviness, due to the deposition speed increase. It was also noticed the presence of ferrite phase in the finer austenite matrix. By increasing the deposition speed, the complete grown equiaxed ferrite (CGEF) grains' structure and, subsequently, mechanical properties have been improved. The double wire feed process was found to be an appropriate process for fabricating the $\mathrm{Cr}-\mathrm{Ni}$ stainless steel components.

Wang [69] studied the influence of the arc modes, namely speed pulse and speed arc, used in the WAAM manufacturing of SS316L stainless steel. The cross-sectional morphology of components showed a structure without defects for both methods. The X-ray photograph of tensile specimens did not exhibit cracking or porosity defects. The microstructure revealed austenite distribution in the primary phase of the WAAM build. The difference in terms of Vickers hardness, for both arc modes, is negligible in the bottom layers. However, because the heat amount increases with subsequent deposition of layers, heat dissipation propagates more slowly. This phenomenon leads to the reduction of secondary dendrite arm spacing (SDAS) and, further, to achieving higher Vickers hardness for speed arc-based WAAM method (Figure 25). The authors reported that UTS and elongation properties are higher for the speed arc method in comparison to the conventional method. 


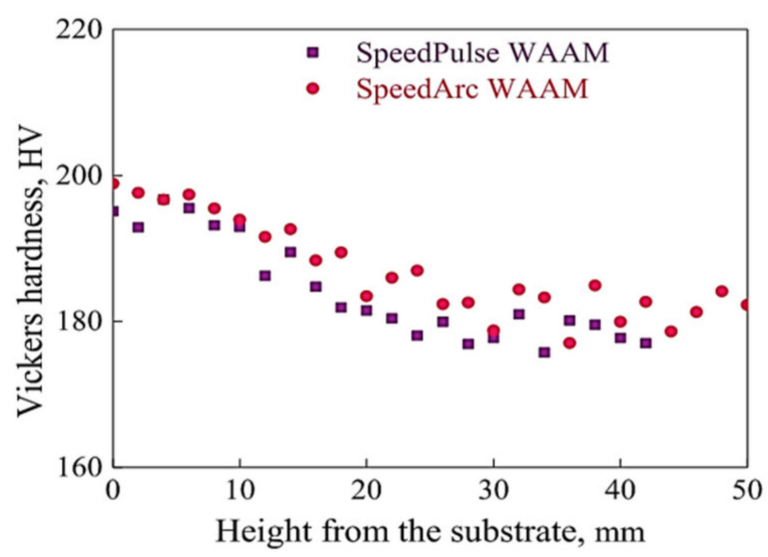

Figure 25. Hardness Characteristics. Reprinted with permission from Ref. [69]. Copyright 2019 Elsevier.

Dirisu et al. [70] analyzed the WAAM fabricated parts of ER70S-6 and established the impact of the rolling process on reducing the surface waviness of the deposited material. It was reported that the compressive stresses, induced by the rolling, reduced the surface waviness and stress concentration, and, consequently, an improved fatigue life was obtained. It was also pointed out that the surface waviness was reduced with increasing the rolling load. As regards the tensile strength, it was found that it is proportional to the rolling load. For instance, applying maximum rolling load, a maximum tensile strength with the least percentage elongation is achieved. The plastic deformation, determined by the rolling process, supports the work-hardening effect that causes the elongation reduction. The hardness is also proportional to the rolling load. It was found that rolling of the deposited surface generates dislocations which cause work-hardening and a reduction of grain size. Moreover, the rolling triggers the austenite nucleation that causes the grain size reduction.

\subsection{Technical Recommendations}

Based on the discussions from the previous sections, it is obvious that the capability to process a wide range of materials is one of the main distinct features of the WAAM process. Due to the great advantage of producing large structural parts in a short time, this manufacturing technique has become more attractive for the manufactures. On the other hand, there are significant issues that can be solved by taking into account the technical solutions specific to the materials approached in this work.

Even if the Ti-based alloys have been found suitable for aerospace applications, with the build parts having a low buy-to-fly ratio, an important issue caused by the development of columnar $\beta$ grains may be the generation of anisotropic properties. The adjustment of the wire feed speed and use of interpass rolling can be the optimal solution to reduce the anisotropy phenomenon. Because of the various thermal histories, recorded during depositing layer by layer, this issue can occur in the WAAM steel alloys parts, too. The anisotropy can be mitigated or completely eliminated by applying pre-heating and postheating treatments, according to the chemical composition of the steel.

An important challenge in the WAAM process of $\mathrm{Al}$ is the existance of the surface oxide film that can be removed by employing an AC supply. However, the polarity reversal leads to generation of turbulence in the melt pool and, consequently, the components achieved may be improper. The use of Ti inoculant or selection of VP-CMT or CMT pulse advanced as heat source, combined with the interlayer rolling, lead to grain refinement and to mitigating the problems in terms of gas pores in Al build parts.

$\mathrm{Ni}$ based alloys, like Inconel 718 or Inconel 625, having a high alloying level, have the tendency to segregate in the interdendritic spaces during the cooling phase. Besides, the mechanical properties can be affected by the formation of $\delta$ phases, but applying a heat treatment, the characteristics of the built parts will be improved. 
In conclusion, the mechanical properties of the build products are governed by the grain's size and structure, as response to the various thermal cycles recorded in the material deposited layer by layer through the WAAM technique. The significant thermal gradients, combined with the epitaxial growth generated in the build parts substrate, determine the development of large columnar grains and, consequently, the occurrence of the anisotropy phenomenon in the deposited material. The main technical measures that can be applied to mitigate this significant issue are the heat treatments and use of inoculants to refine the grain structure.

In conclusion, further advancements in the WAAM process are required in order to improve the knowledge in terms of input heat adjustment and optimization of process parameters by integrating the thermomechanical processing mechanism developed during the deposition process.

\section{Models Developed for Quality Improvement and Process Optimization}

Due to the process dynamics and design difficulties, the optimization and analytical modelling of multi-variable WAAM process parameters are complex and demand good knowledge in the manufacturing field. Nevertheless, the optimization of multi-variable process parameters and thermo-mechanical effects, caused by high deposition rates, is investigated worldwide and more results with varying ranges accuracy were reported. Several mathematical models, described in this chapter, have been developed by researchers worldwide and employed for the analysis of parameters' influence and optimization of the WAAM process. According to the previous discussions on the applications, heat sources and materials used in the WAAM process, the parameters identified to have the most influence on the build parts properties are the material deposition rate, current intensity, wire feed rate, pulsed or continuous mode of electric arcing, and the droplet transfer mode.

Based on the experimental data obtained, Suryakumar et al. [71] developed a seconddegree regression model in which the bead geometry is described as a function of wire and torch speeds and the bead's geometry is assumed to resemble a parabola, as shown in Figure 26. This function was extended to a multi bead deposition model to describe layer thickness and yield in terms of process parameters.

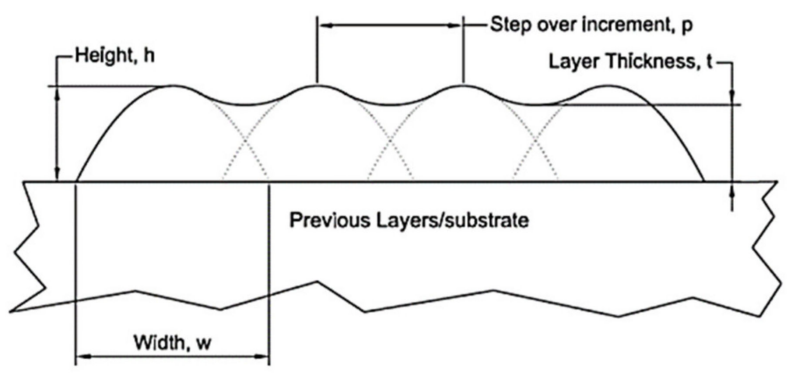

Figure 26. Multi bead profile. Reprinted with permission from Ref. [71]. Copyright 2011 Elsevier.

According to the derived dependency, it was recommended to use minimum wire speed, maximum possible torch speed, and two-thirds of the bead height, as a step over increment for obtaining the required build properties. Because the additional material in the overlapping zone has not been considered in the model, the results were inaccurate and non-reliable. The proposed model was improved with the introduction of a fillet between consecutive beads, Figure 27. The model was validated with varying torch and wire speed experiments on ER70S6 wire of $0.8 \mathrm{~mm}$ diameter and MS substrate with a welding current of 60-120 A. Layered wire deposition was performed with GMAW followed by subtractive $\mathrm{CNC}$ machining to obtain the required design features. 


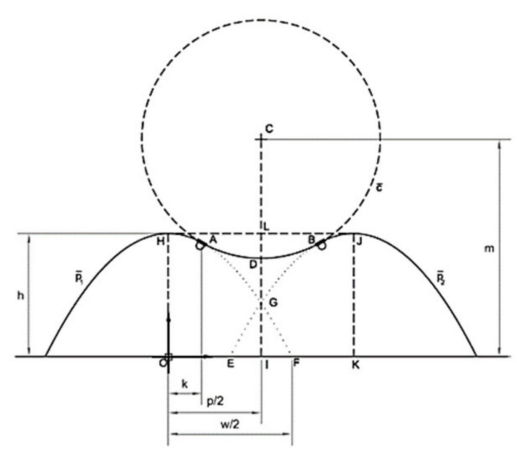

Figure 27. Overlapping parabolic field and fillet. Reprinted with permission from Ref. [71]. Copyright 2011 Elsevier.

Ding et al. [72] developed a single bead model using parabola, cosine and arc functions. Based on the curve fitting of experimental measurements to these models, it was found that the single weld bead could be optimally represented by the parabola and cosine models. Further, the researchers proposed the tangent overlapping model (TOM) shown in Figure 28 which incorporates the concept of critical valley in the multi-bead system, and could predict the critical centre distance for achieving a stable overlapping deposition process with improved accuracy. To obtain and analyse this model, several experiments were conducted using pulsed spray GMAW mode for copper coated steel wire of $1.2 \mathrm{~mm}$ diameter. Varying welding speed in the range of $200-550 \mathrm{~mm} / \mathrm{min}$, a laser profile scanner was used to analyse the profile of the weld beads in the welding direction.

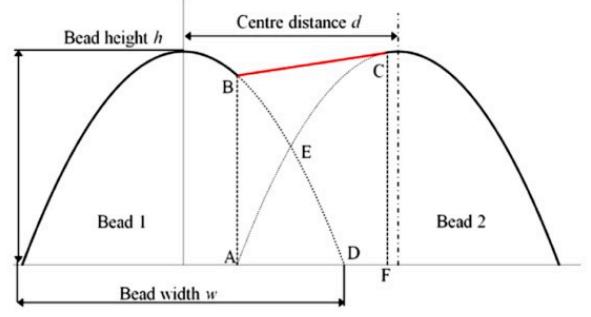

(a)

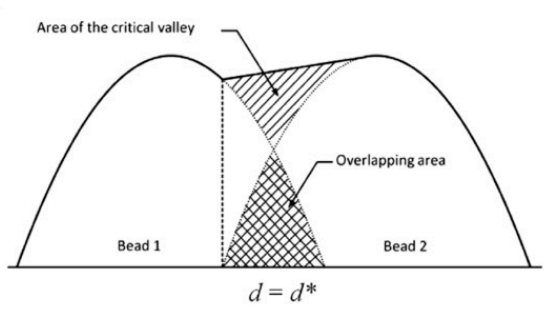

(b)

Figure 28. Tangent Overlapping Model: (a) two weld beads; (b) the overlapped profile. Reprinted from Ref. [72].

Geng et al. [73] developed a theoretical model in order to determine the impact of interpass temperature on the layers depositions. The WAAM process was discretized as a solidifying succession of a series of molten pools. Using the Rosenthal heat model, they derived the maximum temperature at any position to reach the required interpass temperature. The design of the WAAM procedure should be based on the minimum number of layers and the maximum temperature limit to further be used in determining the interpass temperature. Experiments were conducted using a Tungsten inert gas (TIG) machine with a Tetrix Synergic AC/DC wire feeder. A four-axis machine tool was used as a welding manipulator. The wire material used was 5A06 Aluminum alloy of $1.2 \mathrm{~mm}$ diameter. The effect of interpass temperature on the deposited layer surface was studied by preheating the substrate in the temperature range of $50-150{ }^{\circ} \mathrm{C}$. Discontinuous spheres were detected along the weld pass when the interpass temperature was low and smooth layer deposition was achieved when the temperature increased (Figure 29). Figure 30 shows the substrate temperature profile versus time and the stability deposition process after performing 18 layers. 


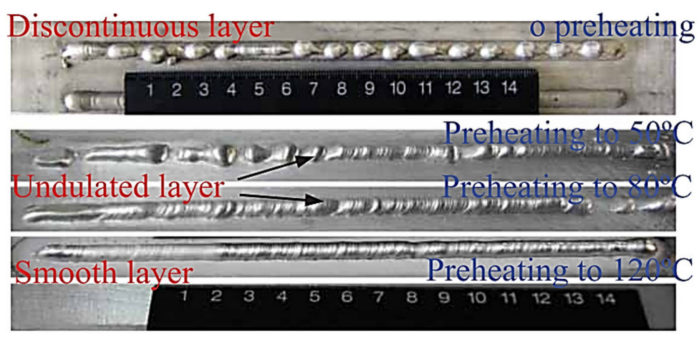

Figure 29. Effect of varying substrate preheating temperature. Reprinted with permission from Ref. [73]. Copyright 2017 Taylor \&Francis Ltd.

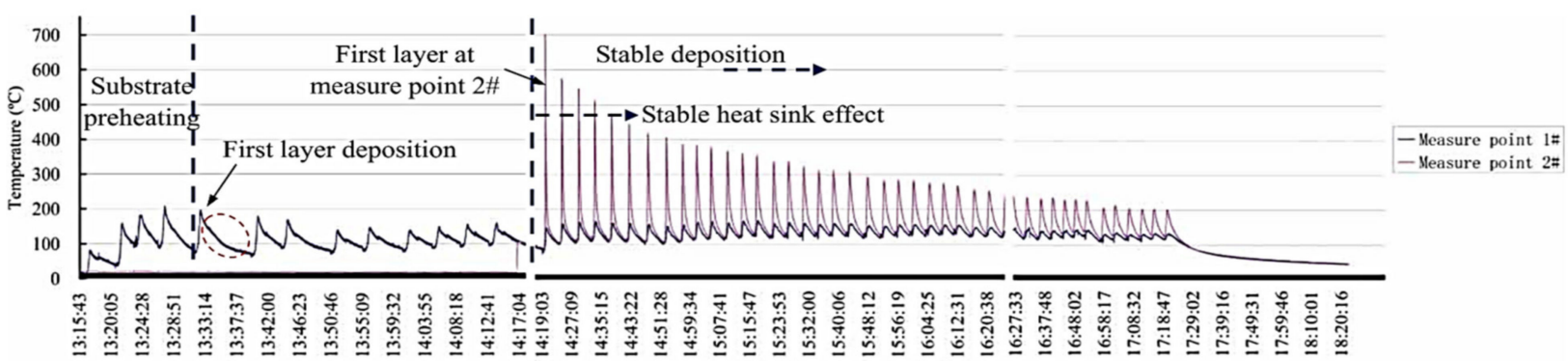

Figure 30. Measured temperature curve. Reprinted with permission from Ref. [73]. Copyright 2017 Taylor \&Francis Ltd.

Guo et al. [74] proposed a classification system for monitoring the quality of WAAM builds. The spectrum technique was used to detect the weld defects and to evaluate the weld pool status. Using an integrated circuit, namely the field programmable gate array (FPGA) and spectrum technique, it was possible to collect the parameters data at the peak current. The classification methods employed in the research were the priori-threshold and k-nearest neighbor (KNN) based on the local preserving projection. The authenticity of the monitoring process with algorithms was established by comparing the experimental results obtained with three different wires. The spectrum method was also applied to monitor the shielding gas flow rate which has significant influence on the weld strength, as well as the impact of the new material deposition (doping-in the form of rust or oil) on the weld quality. Experiments for quality monitoring involved a CMT single pass multi-layer welding machine with 130 A current and three types of welding wires-stainless steel, high strength steel and high nitrogen steel were used. Figure 31 presents the experimental results obtained by applying the spectrum method to detect the defects and to analyze the weld appearance achieved in the case of single pass multi-layer welding of SS.

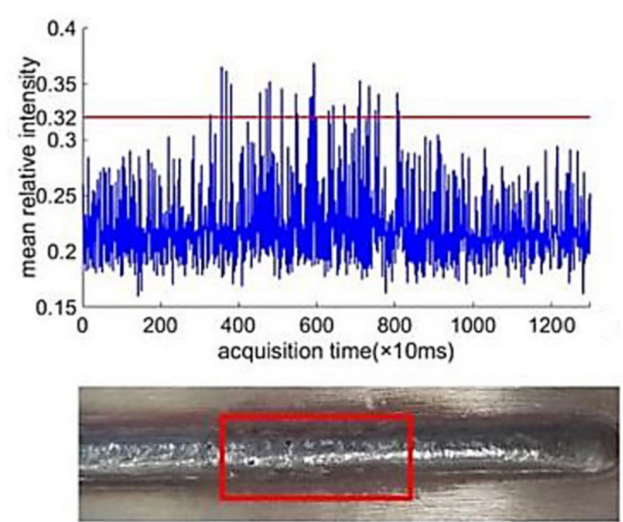

(a)
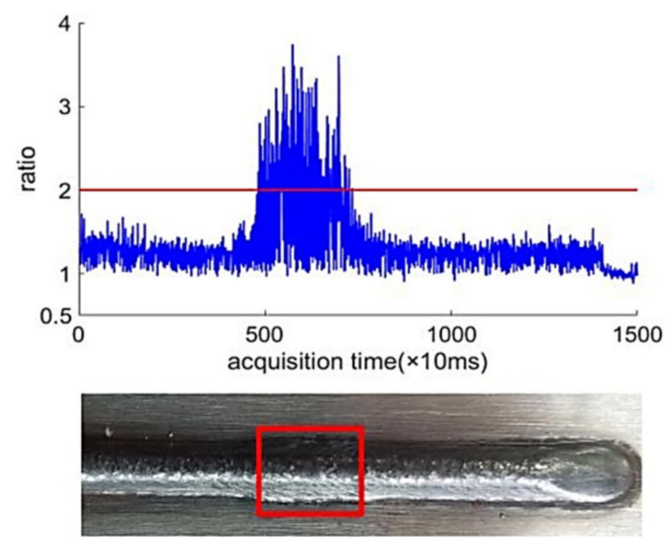

(b)

Figure 31. Spectral data of defects in weld: (a) base metal with or without rust; (b) base metal with or without oil stain. Reprinted with permission from Ref. [74]. Copyright 2019 Elsevier. 
Based on the measurement of the temperature field, generated by a moving point heat source, Rios et al. [75] developed a thermo-capillary model for predicting the layer height and the wall width of the Ti-6Al-4V alloy deposited by plasma and pulsed-TIG WAAM techniques. In the pulsed-TIG technique, independent variables were average current, travel speed, and wire feed speed. In the plasma deposition method, the experimental variables were nozzle design, current and plasma flow rate. Forces acting on the molten pool affect the shape of the pool surface. The weld pool was assumed to be a prismatic liquid body (Figure 32), with hydrostatic pressure and capillary pressure acting on the surface. The model was based on the layer geometry and on the prismatic approximation of the dependence between the net heat input and the deposition dimensions (Figure 33). The predictions, based on the capillarity theory, have been validated by experimental results. It was found that the deposits with radii equal to or smaller than $6 \mathrm{~mm}$ have a cylindrical shape due to surface tension forces. The power requirement was also predicted, with an accuracy of $\pm 20 \%$.

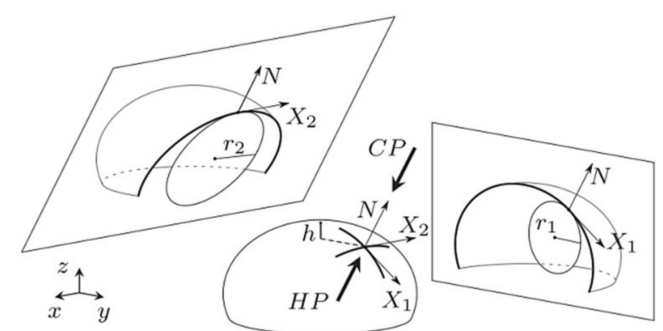

Figure 32. Molten pool surface under the action of forces. Reprinted from Ref. [75].

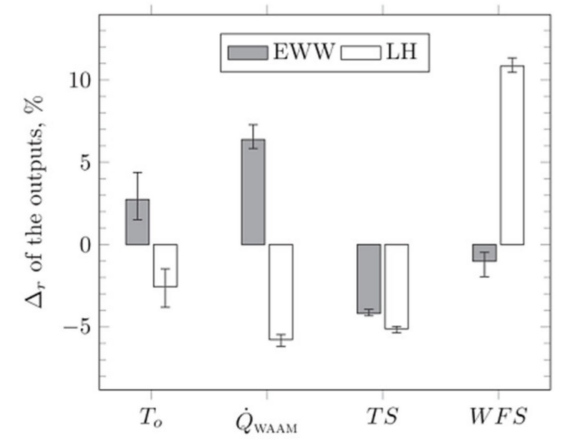

Figure 33. Effect of process parameters on deposit dimensions. Reprinted from Ref. [75].

Based on the response surface methodology (RSM), Tian et al. [76] predicted the surface roughness of the $10 \mathrm{~mm}$ plate of Al2219 alloy builds and explored the feasibility of thermal machining after WAAM. The researchers used a two robots system for implementing WAAM with a GMAW power source and for the milling tool. The RSM was applied to understand the dependency of spindle speed, feed rate and workpiece temperature and, further, to define the machinability in terms of these variables, as Equation (1) shows. The ANOVA method for surface analysis revealed that higher spindle speed and lower feed rate generate a smooth surface.

$$
Y=f\left(f_{z}, n, T\right)+e_{i j}
$$

where $Y$ is the machinability aspect, $n$ the spindle speed, $f_{z}$ the feed rate, and $T$ the workpiece temperature.

Teja et al. [77] employed the grey-based Taguchi method to optimize the mechanical properties of components built from Al6061 substrate and ER4043 MIG wire of $1.2 \mathrm{~mm}$. Several workpieces were CMT fabricated, by varying the gas pressure, current and nozzle to tip distance, based on the L9 orthogonal array. Taguchi analysis was performed for the 
maximization of UTS and to improve the hardness of WAAM samples, and the percentage contribution of each parameter was found by ANOVA analysis. The ANOVA results indicated that the nozzle tip distance significantly affects the WAAM build tensile properties, while the current influences the WAAM build hardness.

Lee et al. [78] employed Gaussian process regression (GPR) to improve both the productivity and the build quality. The wire feed speed, travel speed, and interpass time were considered as input parameters. Based on the input parameters variation, they checked the validity of the GPR model approach, by analyzing the deposition of Ti-6Al-4V straight wall of length $975 \mathrm{~mm}$ using TIG enabled WAAM process. The deposition wire used was $1.2 \mathrm{~mm}$ M-316L and ten wall layers were deposited on AH36 Steel substrate. They reported a wide effective area ratio, minimum height differences, and deposition angle close to 90 degrees (Figure 34). The wire feed rate, travel speed and inter-pass time were considered the main process parameters while the practical value ranges were considered the constraints in the optimization process.
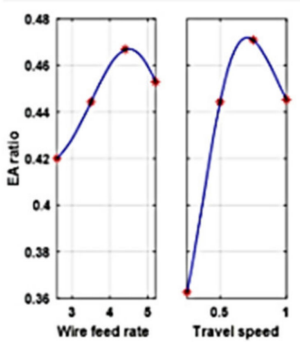

(a)

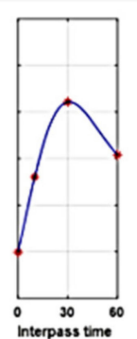

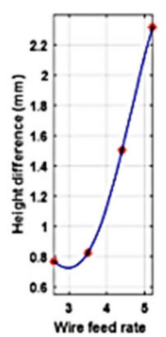

Wre leed rate

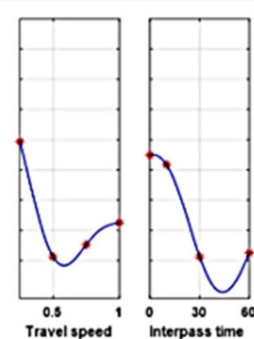

(b)
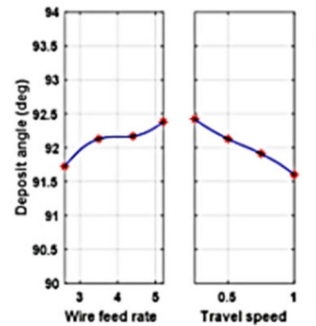

(c)

Figure 34. Output values of GPR vs. wire feed rate, travel speed and interpass time: (a) EA ratio; (b) height difference; (c) deposition angle. Reprinted from Ref. [78].

Based on the machine learning algorithms, Wu et al. [10] developed a mechanical model for identifying and ranking the process parameters and the thermo-mechanical variables which are responsible for the development of stress and strain fields during the WAAM process. The researchers analyzed the data sets for single layer deposits of IN718, SS316 and $800 \mathrm{H}$. Among the main influence factors, the substrate preheat temperature was found to be the key process parameter in comparison to the arc power, substrate thickness, and scanning speed (Figure 35).

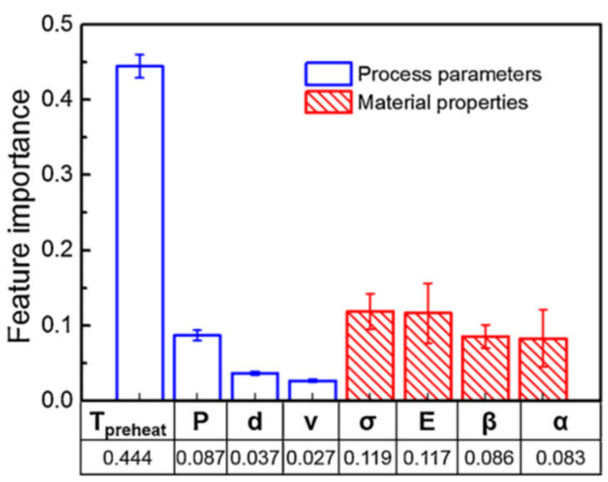

Figure 35. Feature importance of the process parameters. Reprinted with permission from Ref. [10]. Copyright 2020 Elsevier.

The causal parameters are the difference between the solidus and the preheat temperature, liquid pool volume, heat input, substrate rigidity, and the stress developed per unit versus temperature. The process parameter distribution over a large range and the complicated thermomechanical system do not indicate clear dependencies of build properties on 
the parameters. The contribution of the causative parameters responsible for developing the stress and strain is shown in Figure 36.

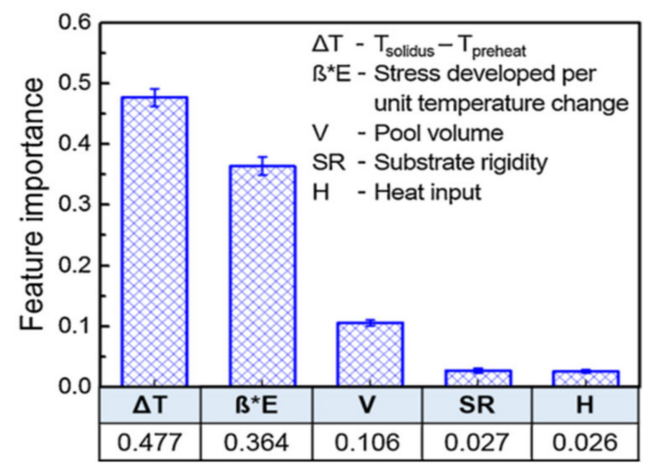

Figure 36. Feature importance of causative parameters. Reprinted with permission from Ref. [10]. Copyright 2020 Elsevier.

Based on the Eulerian frame of reference and on the Lagrangian frame of reference, Ding et al. [1] developed two 3D models for simulating the steady state of the WAAM process and the transient behavior, respectively. The experimental setup for validating the models involved producing walls with mild steel S35JR-AR. Modified MIG (metal inert gas) welding was used based on controlled dip transfer mode powered by CMT heat source. This variant of MIG process enables a high deposition rate with reduced heat input requirement. The FEM models were used to predict the stresses induced in the workpieces by the process. The authors reported an uneven distribution of stresses that can cause high distortions of the structures after the removal of clamps.

Hejripour et al. [79] investigated the mass transport, heat transfer and fluid flow in the dissimilar substrates by modifying the arc travel speed and the feed rate. The experimental set up employed a TIG welding power source with direct current electrode negative (DCEN) for a deposition of $1 \mathrm{~mm}$ diameter Inconel 718 wire on SS substrate. The results revealed that, by increasing the wire feed rate, a higher mixing in the additive layer has been observed. Figure 37 presents the dissipation of heat that generates the compressed and expanded isotherms whose distribution and shape are dependent on the arc travel speed. Due to Marangoni convection and Lorentz forces, the local thermal gradients caused the fluid flow to be inward around the wire inlet and outward at distances far from the filler inlet. The strong whirl creates a well-mixed region at the rear of the weld pool which solidifies as the cladding layer (Figure 37).
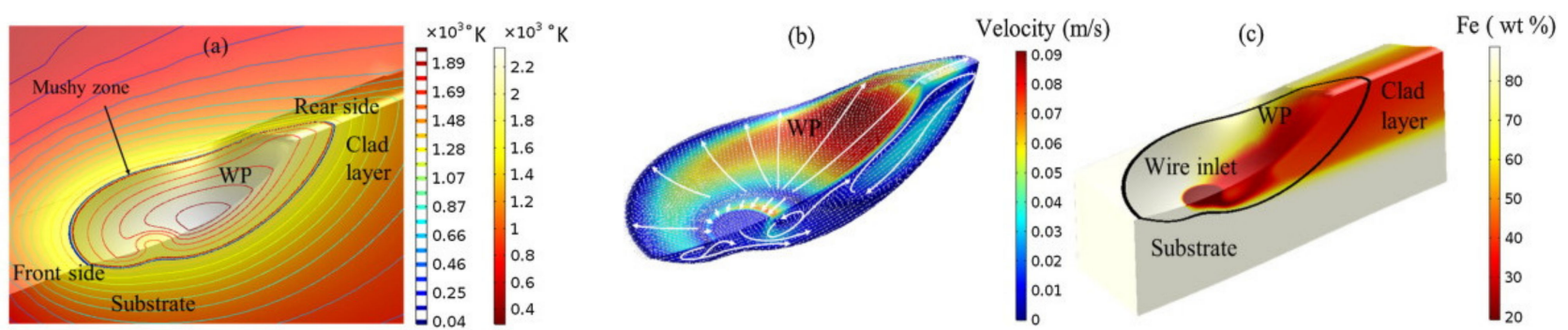

Figure 37. Three-dimensional view of the numerical prediction of the temperature field, velocity field and mass distribution: (a) temperature isoterms; (b) velocity field; (c) mixing phenomena (iron mixture) in the weld pool. Reprinted from Ref. [79].

Hejripour et al. [80] explored the WAAM based directed energy deposition (DED) process employed to build two parts, namely the tube and the wall, from 2209 Duplex Stainless Steel. The system used in this study is a semi-automatic MIG system with 2209 DSS wire of $0.9 \mathrm{~mm}$ at a deposition rate of $2.38 \mathrm{~kg} / \mathrm{hr}$. The direction of layer deposition 
was reversed for each layer with no inter layer idle time. The aim of the research was to promote the ferrite phase formation by monitoring the process parameters and the cooling rate. To control the formation of ferrite phase, 3D transient thermal models of the additive manufactured (AM) parts for the simulation of thermal cycles and prediction of temperature distribution were developed. The correlation between the cooling rate and the ferrite phase formation revealed that slow cooling rates of the built layers, at elevated temperatures, promote austenite formation in the ferrite matrix, as shown in Figure 38. The investigation of the microstructural and mechanical behavior showed good fusion and comparable material properties, such as tensile strength, flexural strength, and stiffness, to wrought counter-parts.
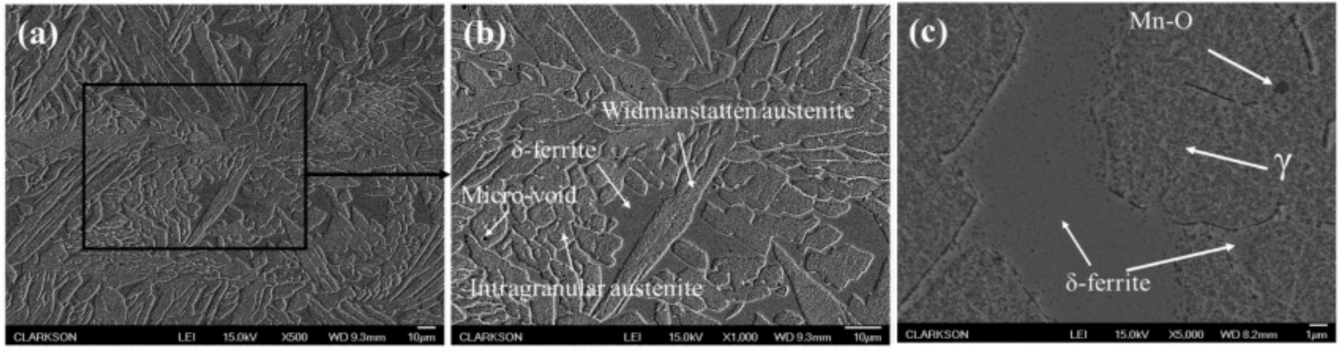

Figure 38. SEM image of one of the middle layer: (a) magnification $\times 500$; (b) magnification $\times 1000$; (c) magnification $\times 2000$. Reprinted from Ref. [80].

Li et al. [81] proposed a method, based on an enhanced Beads Overlapping Model (BOM), for planning the deposition paths (Figure 39). The model simulates the spreading of the melted weld beads caused by the weld pool surface tension that deviates the weld bead center from the wire feed center. The experimental setup comprised a six-axis robot based WAAM system for deposition of $1.2 \mathrm{~mm}$ copper coated steel wire on Q235 substrate. Substrate material dimensions were $200 \mathrm{~mm} \times 150 \mathrm{~mm} \times 10 \mathrm{~mm}$ and a mixture of Ar and $\mathrm{CO}_{2}$ at the flow rate of $18 \mathrm{~L} / \mathrm{min}$ was used as shielding gas. Stable deposition process was maintained with nozzle to substrate distance of $12 \pm 0.3 \mathrm{~mm}$. Based on the artificial neural network (ANN), a closed loop iteration algorithm was created to predict the offset distance for a particular weld bead.

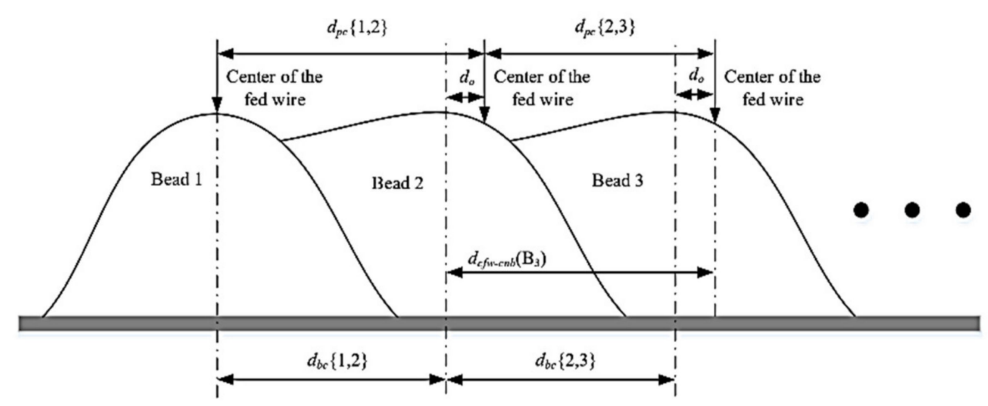

Figure 39. Enhanced bead overlapping model Reprinted with permission from Ref. [80]. Copyright 2018 Elsevier.

Li et al. [82] presented more information on the layer overlapping process of inclined multi-layer multi-bead (MLMB) parts which was performed by WAAM without requiring face milling after each layer deposition (Figure 40). The concept of rotating the depositing torch and the supporting table was utilized for inclined structure fabrication. The experimental setup for evaluating the model consisted of a six-axis robot, GMAW power supply, wire feeding machine and YD500R welding machine. The wire used for deposition is the $1.2 \mathrm{~mm}$ diameter copper coated steel wire and Q235 was used as substrate material. Experiments were designed with different parameters and orientations of the deposit on the first and the last beads of the layers. A mathematical model for layer-overlapping 
that considers the material shortage areas at the edges of the layers was proposed by the authors. Various inclination angles and slope spart from the material shortage at the edges of layers, have been considered in the model. It was concluded that the deposition order of the beads has a significant impact on the shape formation of negative slopes. Sections having material shortage which get formed at the edges and the surface unevenness of the top layer are the two main fabrication challenges faced by the model (Figure 41). Both issues were solved by depositing a cover layer on the top.

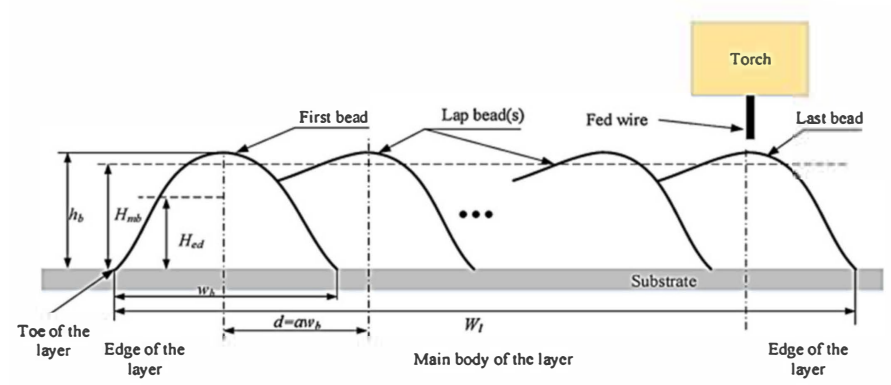

(a)

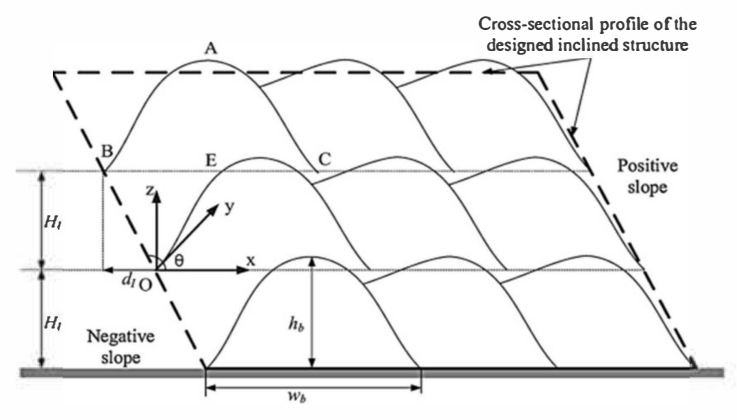

(b)

Figure 40. Geometric model of the cross-section profile of inclined MLMB structure: (a) base model; (b) geometrical model. Reprinted with permission from Ref. [82]. Copyright 2018 Elsevier.

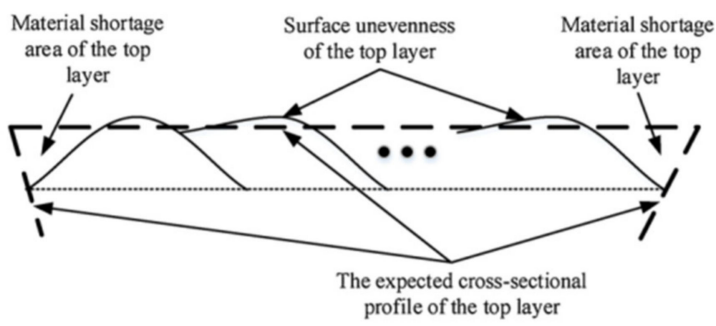

Figure 41. Fabrication issues on the top layer. Reprinted with permission from Ref. [82]. Copyright 2018 Elsevier.

Based on the displacement compensation method, Geng et al. [83] provided a mathematical model useful in improving the deposition accuracy and in achieving a smooth deposition in the side-feed direction. The experimental setup consisted of TIG machine with wire feed mechanism illustrated in Figure 42. The wire adjusting tolerance $h$ and the wire feed angle $\theta$ were controlled for different droplet transfer modes. A four-axis computer numerical controller (CNC) machine was used as torch navigator. 5A06 Al alloy wire of $1.2 \mathrm{~mm}$ was used for deposition on the $300 \mathrm{~mm} \times 200 \mathrm{~mm} \times 15 \mathrm{~mm}$ substrate. The supply used was rectangular pulse AC, $50 \mathrm{~Hz}$ with a peak current of $160 \mathrm{~A}$ and background current of $120 \mathrm{~A}$. The wire feed speed was maintained at $2 \mathrm{~m} / \mathrm{min}$ and the torch travel speed at $300 \mathrm{~mm} / \mathrm{min}$.

Figure 43 presents the arc shape and the heat flux distribution modelling, though the arc is considered a point heat source for simulating the wire melting. Taking into consideration the wire feeding and melting, the authors determined the wire flying distance with varying the nozzle to substrate distance (NTSD). Another technique is the adjustment of wire feed manner, while maintaining the displacement compensation, to achieve the bridge transfer (Figure 43). 


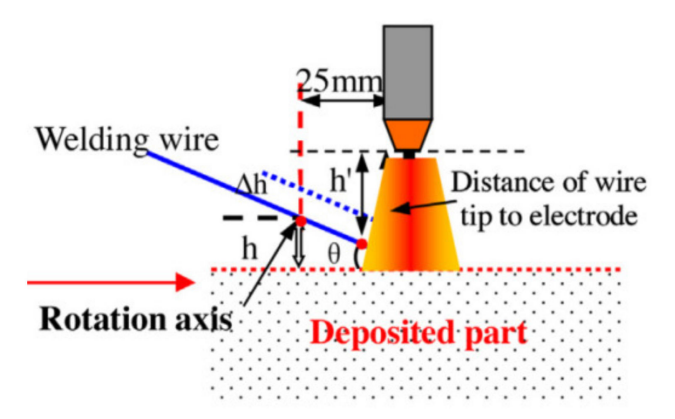

Figure 42. Schematic of Wire feed unit. Reprinted with permission from Ref. [83]. Copyright 2017 Elsevier.

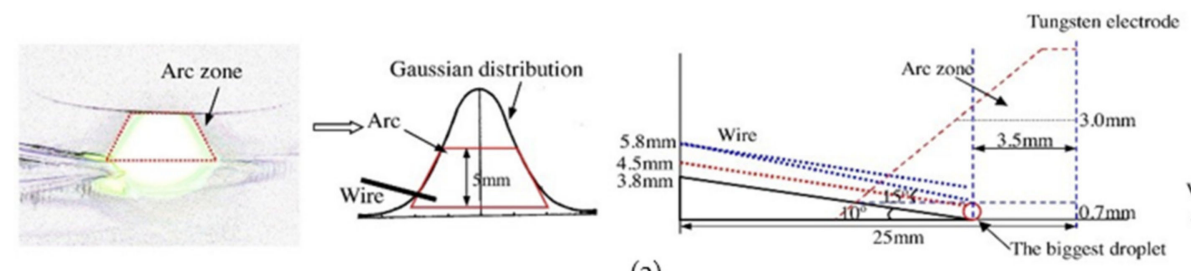

(a)

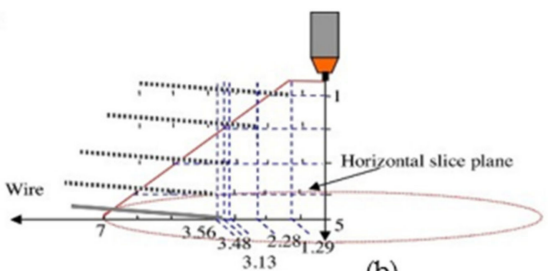

(b)

Figure 43. Mechanism for wire feed variation for bridge transfer: (a) arc modelling; (b) wire feed optimisation and displacement compensation. Reprinted with permission from Ref. [83]. Copyright 2017 Elsevier.

Oyama et al. [84] simulated the WAAM process for the Al-5Mg and Al-3Si alloys with the aim of optimizing the layers deposition sequence and the deposition parameters. The experiment procedure involved the construction of separate $200 \mathrm{~mm}$ walls with CMT powered WAAM system. Open circuit voltage was maintained at $15-18 \mathrm{~V}$ with and the travel speed at 6-8 mm/sec. Semi-automatic deposition mode was adopted to have considerable delay between the inter layer depositions to ensure a lowering of the temperature before the deposition. The authors reported that by changing the direction of every layer deposition, a symmetric distribution of stress field was achieved. This was attributed to the uninterrupted deposition process that entails modification of the heat input for each layer and to the heat source staying longer on the wall structure edges. It was further noticed that the size of the molten pool was stabilized when the heat adjustment and the interlaced depositions were applied.

Montevecchi et al. [85] proposed a technical solution to solve the issue of heat accumulation, by impinging air jet through a vortex that cools the workpiece. A numerical model of jet impingement cooling was applied to a finite element thermal model of the WAAM process, with the aim of assessing the effectiveness of this cooling system. The numerical model was validated through the thermography method using an Exair vortex tube fed by a compressed air flow to cool a S235JR plate. Based on the comparative analysis of numerical and experimental results, illustrated in Figure 44, the authors reported a good accuracy of the model. The research outcomes highlight that the heat accumulation could be prevented by controlling the inter-pass temperature across the layers and the size of the molten pool.

The approach on the predictive models, developed for the simulation of the WAAM process, demonstrates the effectiveness of their employing in improving the process performances which are strongly dependent on the multiple process parameters, materials and workpieces shape. Various statistical methods have been applied to determine the optimal parameters and the influential factors for the desired multiple responses. The mathematical models provide information on the correlation between the responses and the process parameters at confidence level of almost $95 \%$. The main aim of the modelling is to facilitate the complex design, testing in different conditions of static and dynamic loading, reproducibility in the geometry of materials and to check the interdependencies between different interdisciplinary parameters. Moreover, the modelling method minimizes 
the costs incurred by the experimental programs and eliminates the practical existence of materials.
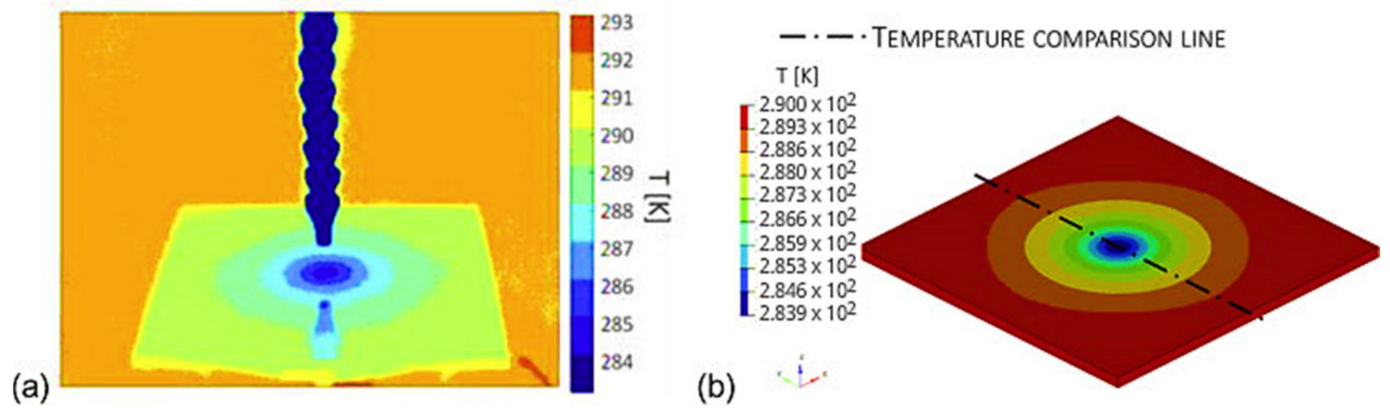

Figure 44. Transient Temperature: (a) IR image; (b) FE temperature profile. Reprinted with permission from Ref. [85]. Copyright 2018 Elsevier.

\section{Constraints and Proposed Enhancements regarding the WAAM Process}

Despite innumerable favorable features, the WAAM process reveals some constraints and challenges for industry that has to develop further research before the deployment of technologies. Several researchers have proposed mechanisms to reduce the number of constraints and to improve the mechanical properties and the microstructural integrity of the WAAM builds (Table 1).

Due to the high deposition rate and shorter time to manufacture large metal parts, this process may be employed and extended in many industrial sectors. However, many disadvantages, in terms of process constraints and limitations, could be eliminated only by continuing the experimental research and developing various combinations of process configurations and materials to be melted and deposited by WAAM method. The application of the proposed redressal techniques can mitigate the distortion and residual stress field and other challenges encountered in the WAAM process. Moreover, the researchers' findings reveal an improved quality of WAAM build parts along with cost and build time savings. 
Table 1. Constraints and limitations in the WAAM process.

\begin{tabular}{|c|c|c|c|c|}
\hline Ref No. & WAAM Constraint Addressed & Proposed Redressal Scheme & $\begin{array}{l}\text { Effect on Microstructure/Mechanical } \\
\text { Properties }\end{array}$ & Demerits/Limitations \\
\hline \multicolumn{5}{|c|}{ Raw Material } \\
\hline [86] & Limited availability of feedstock wires & $\begin{array}{l}\text { Production of AA6061 by } \\
\text { friction extrusion }\end{array}$ & $\begin{array}{l}\text { Microstructure-strength and hardness } \\
\text { comparable to standard WAAM with } \\
\text { AA6061 base metal }\end{array}$ & $\begin{array}{l}\text { Presence of voids and bends in extruded } \\
\text { wires. To eliminate twisting, drawing wire } \\
\text { more than once required }\end{array}$ \\
\hline [87] & $\begin{array}{l}\text { Feasibility and crack sensitivity of } \\
\text { hybrid parts manufacturing }\end{array}$ & $\begin{array}{l}\text { Production of Nickel Aluminum } \\
\text { Bronze-Stainless Steel hybrid parts }\end{array}$ & $\begin{array}{l}\text { Fine equiaxed alpha dendrites, good } \\
\text { surface properties }\end{array}$ & $\begin{array}{l}\text { Inter-metallics formation, penetration of } \\
\text { NAB along the HAZ cracks, rosette like } \\
\text { particles due to dilution defects-negatively } \\
\text { affecting toughness and ductility }\end{array}$ \\
\hline \multicolumn{5}{|c|}{ Deposition Method } \\
\hline [41] & $\begin{array}{l}\text { To overcome freeform manufacturing } \\
\text { issues of collision, deposited material } \\
\text { causing obstruction and overlapping } \\
\text { points at intersections. }\end{array}$ & $\begin{array}{l}\text { Local control on geometry of deposition } \\
\text { by on-line adaptive slicing and deposition } \\
\text { strategies to manage branch intersections }\end{array}$ & $\begin{array}{l}\text { Yielded appropriate positioning of } \\
\text { skeleton freeform branches in intersection. } \\
\text { In-situ monitoring enables online } \\
\text { gap-checking and required weld torch } \\
\text { orientation. }\end{array}$ & - \\
\hline [83] & $\begin{array}{c}\text { Deposition Accuracy inside feed } \\
\text { orientation }\end{array}$ & $\begin{array}{l}\text { Displacement compensation \& wire feed } \\
\text { angle manipulation }\end{array}$ & $\begin{array}{l}\text { Consistent layer deposition, control of } \\
\text { droplet landing position }\end{array}$ & $\begin{array}{l}\text { Chance of wire getting flexed through the } \\
\text { arc column }\end{array}$ \\
\hline [88] & $\begin{array}{l}\text { Residual Stress, manual control for the } \\
\text { same layer height }\end{array}$ & $\begin{array}{l}\text { Deposition path definition for } \\
\text { T-cross builds }\end{array}$ & $\begin{array}{l}\text { Increased utilization, increased failure of? } \\
\text { free parts, deposition efficiency }\end{array}$ & $\begin{array}{c}\text { Balance between productivity and material } \\
\text { usage efficiency }\end{array}$ \\
\hline \multicolumn{5}{|c|}{ Stress \& Distortion } \\
\hline [89] & Residual stresses and distortion & Inter-pass rolling & $\begin{array}{l}\text { Increase in wall width, uniform } \\
\text { layer height }\end{array}$ & Increased manufacturing time \\
\hline$[90]$ & $\begin{array}{l}\text { High porosity, coarse microstructure, } \\
\text { low mechanical performance }\end{array}$ & Workpiece vibration & $\begin{array}{c}\text { Dendrite breakage and grain refinement, } \\
\text { reduced porosity, improved } \\
\text { tensile properties }\end{array}$ & $\begin{array}{l}\text { Elongation and anisotropy } \\
\text { negatively affected }\end{array}$ \\
\hline [91] & Tensile stresses & Interpass rolling and thermal stress relief & $\begin{array}{l}\text { Improved mechanical properties with } \\
\text { reduced grain size }\end{array}$ & $\begin{array}{l}\text { Dominant thermal history, no significant } \\
\text { difference to final residual stress }\end{array}$ \\
\hline [92] & Part Distortion & $\begin{array}{l}\text { Inter-pass cooling using compressed } \mathrm{CO}_{2} \\
\text { To be considered in the path planning } \\
\text { strategy for improved geometry }\end{array}$ & Improved dimensional accuracy & $\begin{array}{l}\text { Change in } \mathrm{CO}_{2} \text { gas flow rate may cause } \\
\text { in-homogenous stress and distortion to the } \\
\text { build. Unrestrained shrinkage prevents } \\
\text { complete distortion elimination }\end{array}$ \\
\hline
\end{tabular}


Table 1. Cont.

\begin{tabular}{|c|c|c|c|c|}
\hline Ref No. & WAAM Constraint Addressed & Proposed Redressal Scheme & $\begin{array}{l}\text { Effect on Microstructure/Mechanical } \\
\text { Properties }\end{array}$ & Demerits/Limitations \\
\hline \multicolumn{5}{|c|}{ Heat Source Design } \\
\hline [85] & Heat Accumulation & $\begin{array}{l}\text { Impinging air jets through a vortex to } \\
\text { increase convective heat transfer }\end{array}$ & $\begin{array}{l}\text { Effective control of the inter-pass } \\
\text { temperature, excessive increase in molten } \\
\text { pool size }\end{array}$ & $\begin{array}{l}\text { Needs to be investigated for complex } \\
\text { configurations }\end{array}$ \\
\hline [93] & $\begin{array}{l}\text { Surface Cracking because of various } \\
\text { factors such as alloy composition, high } \\
\text { wire feed speed }\end{array}$ & $\begin{array}{l}\text { Influence of composition, heat input, } \\
\text { mechanical properties studied }\end{array}$ & $\begin{array}{l}\text { Proposed model can predict solidification } \\
\text { cracking tendency, higher microhardness } \\
\text { reduces crack susceptibility }\end{array}$ & Insufficient feed causes crack initiation \\
\hline$[94]$ & Dimensional inaccuracy & $\begin{array}{l}\text { Laser assisted WAAM-leading/trailing } \\
\text { laser beam }\end{array}$ & $\begin{array}{l}\text { Improved surface topology, dense } \\
\text { samples with no porosity }\end{array}$ & $\begin{array}{c}\text { Increased experimentation and simulation } \\
\text { trials, excessive melting may cause } \\
\text { premature deposition }\end{array}$ \\
\hline [95] & $\begin{array}{l}\text { Process instability, inaccurate } \\
\text { build geometry }\end{array}$ & Magnetic arc oscillation & $\begin{array}{l}\text { Homogenous thin wall depositions } \\
\text { achieved, reduced power density, } \\
\text { reduced volume and weight of weld pool, } \\
\text { reduced solidification time }\end{array}$ & $\begin{array}{l}\text { Surface variation due to varying } \\
\text { arc position }\end{array}$ \\
\hline [96] & $\begin{array}{l}\text { Irregularities in the build structure } \\
\text { because of thermal gradients }\end{array}$ & $\begin{array}{l}\text { Multilayer laser assisted WAAM to study } \\
\text { impact of different lead angles and } \\
\text { interlayer temperatures. Also studied } \\
\text { effect of variation in dragging and } \\
\text { pushing WAAM process }\end{array}$ & $\begin{array}{l}\text { Wider melt pool, better track wetting on } \\
\text { the substrate, optimum lead angle } \\
\text { identified as } 10 \text { degrees }\end{array}$ & $\begin{array}{c}\text { Fluctuations observed at lead angles other } \\
\text { than } 10 \text { degrees and at higher interlayer } \\
\text { temperatures in dragging WAAM } \\
\text { processsmakal }\end{array}$ \\
\hline [97] & $\begin{array}{l}\text { Slow manufacturing Speed because of } \\
\text { cooling techniques }\end{array}$ & $\begin{array}{l}\text { Aerosol cooling during the } \\
\text { manufacturing }\end{array}$ & $\begin{array}{l}\text { No porosity or weld defects highlighted, } \\
\text { Weld seam shape and dendritic structure } \\
\text { are similar, smaller dendrites and higher } \\
\text { hardness compared to uncooled weld }\end{array}$ & $\begin{array}{l}\text { Unsteady drops in temperature, } \\
\text { asymmetric weld seam shape }\end{array}$ \\
\hline
\end{tabular}




\section{Conclusions}

Based on a large number of recent articles published in the wire arc additive manufacturing field, this review article provides an overall view of the progress made and information useful to researchers worldwide interested in obtaining new findings. To enhance the acceptability and the applicability of the WAAM process for a wide variety of custom-made large size metallic builds performed from materials such as Ti-6Al-4V alloy, Inconel, Chromium, having properties close to the wrought or cast parts, more experimental research to improve the knowledge is needed. Besides, exploring the possible applicability of the WAAM process for repairing large metallic structures would be advantageous in terms of maintenance and service costs.

Currently, there is a lack of WAAM benchmark indicators, in comparison with other manufacturing techniques, but the potential in terms of digital fabrication versus the traditional manufacturing process is evident. The mass and high-quality production of WAAM is achievable if the issues related to high levels of heat input are mitigated and constraints and limitations are eliminated.

The residual stress and distortion are the primary limiting factors affecting the acceptability and adaptability of the WAAM process in major industries. Advanced computational techniques based on data learning can be explored for development of efficient techniques.

With the integration of possible enhancements, in-situ monitoring, and non-destructive inline evaluation, this process can be an attractive option for producing a large range of prototype constructions. Besides, the process promises significant reduction in material wastage and cost, as well as an increased freedom of design, customization and components complexity. The precise design can facilitate an accurate optimization of the process, while the investigation of depositing different metals wires by WAAM method increases the knowledge level in the fields of materials optimization and multi-material components fabrication. By integrating the machining platform with the AM process, the creation and fabrication of complexed shapes can become more and more easily performed. Presently, the WAAM process is under continuous investigation with the aim to identify the feasibility for various materials, shapes, and applications. Neither a net-shape nor automated process are complete until the commercial AM CAD/CAM software is available in its fully developed version. The entire fabrication process, from the conception of part models and interpretation to the design and preparation of a manufacturing procedure, demands skilled operators. Nevertheless, in comparison to the conventional welding, cladding, or subtractive manufacturing techniques, the WAAM process provides a high degree of flexibility, high economic efficiency, and a high rate of using the additional material. Further, the capability to fabricate large metal 3D printed components and deployment for light materials increase the attention paid by industry towards the WAAM technique.

Author Contributions: Conceptualization, M.C. and A.V.S.; methodology, M.C. and A.V.S.; formal analysis, M.C. and L.R.M.; investigation, M.C. and A.V.S.; resources, M.C., A.V.S., D.M., and L.R.M.; writing-original draft preparation, M.C. and A.V.S.; writing-review and editing, E.S., C.C.R., and D.M.; visualization, E.S. and C.C.R.; supervision, E.S. All authors have read and agreed to the published version of the manuscript.

Funding: This research received no external funding.

Institutional Review Board Statement: Not applicable.

Informed Consent Statement: Not applicable.

Data Availability Statement: Not applicable.

Acknowledgments: The authors gratefully acknowledge the support received from Dayananda Sagar University, India and "Dunarea de Jos" University of Galati, Romania.

Conflicts of Interest: The authors declare no conflict of interest. 


\section{References}

1. Ding, J.; Colegrove, P.; Mehnen, J.; Ganguly, S.; Almeida, P.S.; Wang, F.; Williams, S. Thermo-mechanical analysis of Wire and Arc Additive Layer Manufacturing process on large multi-layer parts. Comput. Mater. Sci. 2011, 50, 3315-3322. [CrossRef]

2. Ríos, S.; Colegrove, P.A.; Williams, S.W. Metal transfer modes in plasma Wire + Arc additive manufacture. J. Mater. Process. Technol. 2019, 264, 45-54. [CrossRef]

3. Zhang, C.; Li, Y.; Gao, M.; Zeng, X. Wire arc additive manufacturing of Al-6Mg alloy using variable polarity cold metal transfer arc as power source. Mater. Sci. Eng. A 2018, 711, 415-423. [CrossRef]

4. Bekker, A.C.; Verlinden, J.C.; Galimberti, G. Challenges in assessing the sustainability of wire+ arc additive manufacturing for large structures. In Proceedings of the Solid Freeform Fabrication Symposium, Austin, TX, USA, 8-10 August 2016; pp. 406-418.

5. Michel, F.; Lockett, H.; Ding, J.; Martina, F.; Marinelli, G.; Williams, S. A modular path planning solution for Wire + Arc Additive Manufacturing. Robot. Comput. Integr. Manuf. 2019, 60, 1-11. [CrossRef]

6. Li, J.L.Z.; Alkahari, M.R.; Rosli, N.A.B.; Hasan, R.; Sudin, M.N.; bin Ramli, F.R. Review of Wire Arc Additive Manufacturing for 3D Metal Printing. Int. J. Autom. Technol. 2019, 13, 346-353. [CrossRef]

7. Zhang, J.; Liou, F.W. Multi-Axis Planning of a Hybrid Material Deposition and Removal Combined Process. J. Mach. Manuf. Autom. 2013, 2, 46-57.

8. Challenges \& Latest Developments in Wire + Arc Additive Manufacturing. Available online: https://www.tctmagazine.com/ additive-manufacturing-3d-printing-news / challenges-latest-developments-wire-arc-additive-manufacturing (accessed on 25 December 2020).

9. Cunningham, C.; Flynn, J.; Shokrani, A.; Dhokia, V.; Newman, S. Invited review article: Strategies and processes for high quality wire arc additive manufacturing. Addit. Manuf. 2018, 22, 672-686. [CrossRef]

10. Wu, Q.; Mukherjee, T.; De, A.; DebRoy, T. Residual stresses in wire-arc additive manufacturing—Hierarchy of influential variables. Addit. Manuf. 2020, 35, 101355. [CrossRef]

11. Busachi, A.; Erkoyuncu, J.; Colegrove, P.; Martina, F.; Ding, J. Designing a WAAM Based Manufacturing System for Defence Applications. Procedia CIRP 2015, 37, 48-53. [CrossRef]

12. Lockett, H.; Ding, J.; Williams, S.; Martina, F. Design for Wire + Arc Additive Manufacture: Design rules and build orientation selection. J. Eng. Des. 2017, 28, 568-598. [CrossRef]

13. Yuan, L.; Ding, D.; Pan, Z.; Yu, Z.; Wu, B.; Van Duin, S.; Li, H.; Li, W. Application of Multidirectional Robotic Wire Arc Additive Manufacturing Process for the Fabrication of Complex Metallic Parts. IEEE Trans. Ind. Inform. 2019, 16, 454-464. [CrossRef]

14. Müller, J.; Grabowski, M.; Müller, C.; Hensel, J.; Unglaub, J.; Thiele, K.; Kloft, H.; Dilger, K. Design and Parameter Identification of Wire and Arc Additively Manufactured (WAAM) Steel Bars for Use in Construction. Metals 2019, 9, 725. [CrossRef]

15. Abe, T.; Sasahara, H. Layer geometry control for the fabrication of lattice structures by wire and arc additive manufacturing. Addit. Manuf. 2019, 28, 639-648. [CrossRef]

16. Chandrasekaran, S.; Hari, S.; Amirthalingam, M. Wire arc additive manufacturing of functionally graded material for marine risers. Mater. Sci. Eng. A 2020, 792, 139530. [CrossRef]

17. Lin, J.; Lv, Y.; Liu, Y.; Sun, Z.; Wang, K.; Li, Z.; Wu, Y.; Xu, B. Microstructural evolution and mechanical property of Ti-6Al-4V wall deposited by continuous plasma arc additive manufacturing without post heat treatment. J. Mech. Behav. Biomed. Mater. 2017, 69, 19-29. [CrossRef] [PubMed]

18. Priarone, P.C.; Pagone, E.; Martina, F.; Catalano, A.R.; Settineri, L. Multi-criteria environmental and economic impact assessment of wire arc additive manufacturing. CIRP Ann. 2020, 69, 37-40. [CrossRef]

19. Prado-Cerqueira, J.; Diéguez, J.; Camacho, A. Preliminary development of a Wire and Arc Additive Manufacturing system (WAAM). Procedia Manuf. 2017, 13, 895-902. [CrossRef]

20. Shukla, P.; Dash, B.; Kiran, D.V.; Bukkapatnam, S. Arc Behavior in Wire Arc Additive Manufacturing Process. Procedia Manuf. 2020, 48, 725-729. [CrossRef]

21. Xiong, J.; Lei, Y.; Chen, H.; Zhang, G. Fabrication of inclined thin-walled parts in multi-layer single-pass GMAW-based additive manufacturing with flat position deposition. J. Mater. Process. Technol. 2017, 240, 397-403. [CrossRef]

22. Luo, Y.; Li, J.; Xu, J.; Zhu, L.; Han, J.; Zhang, C. Influence of pulsed arc on the metal droplet deposited by projected transfer mode in wire-arc additive manufacturing. J. Mater. Process. Technol. 2018, 259, 353-360. [CrossRef]

23. Zhu, L.; Luo, Y.; Han, J.; Zhang, C.; Xu, J.; Chen, D. Energy characteristics of droplet transfer in wire-arc additive manufacturing based on the analysis of arc signals. Measurement 2019, 134, 804-813. [CrossRef]

24. Guo, M.; Jia, C.; Zhou, J.; Liu, W.; Wu, C. Investigating the generation process of molten droplets and arc plasma in the confined space during compulsively constricted WAAM. J. Mater. Process. Technol. 2020, 275, 116355. [CrossRef]

25. Marinelli, G.; Martina, F.; Ganguly, S.; Williams, S. Grain refinement in an unalloyed tantalum structure by combining Wire+Arc additive manufacturing and vertical cold rolling. Addit. Manuf. 2020, 32, 101009. [CrossRef]

26. Abe, T.; Kaneko, J.; Sasahara, H. Thermal sensing and heat input control for thin-walled structure building based on numerical simulation for wire and arc additive manufacturing. Addit. Manuf. 2020, 35, 101357. [CrossRef]

27. Huang, J.; Yuan, W.; Yu, S.; Zhang, L.; Yu, X.; Fan, D. Droplet transfer behavior in bypass-coupled wire arc additive manufacturing. J. Manuf. Process. 2020, 49, 397-412. [CrossRef] 
28. Li, S.; Zhang, L.-J.; Ning, J.; Wang, X.; Zhang, G.-F.; Zhang, J.-X.; Na, S.-J.; Fatemeh, B. Comparative study on the microstructures and properties of wire+arc additively manufactured 5356 aluminium alloy with argon and nitrogen as the shielding gas. Addit. Manuf. 2020, 34, 101206. [CrossRef]

29. Yang, D.; He, C.; Zhang, G. Forming characteristics of thin-wall steel parts by double electrode GMAW based additive manufacturing. J. Mater. Process. Technol. 2016, 227, 153-160. [CrossRef]

30. Mok, S.H.; Bi, G.; Folkes, J.; Pashby, I. Deposition of Ti-6Al-4V using a high power diode laser and wire, Part I: Investigation on the process characteristics. Surf. Coat. Technol. 2008, 202, 3933-3939. [CrossRef]

31. Dinovitzer, M.; Chen, X.; Laliberte, J.; Huang, X.; Frei, H. Effect of wire and arc additive manufacturing (WAAM) process parameters on bead geometry and microstructure. Addit. Manuf. 2019, 26, 138-146. [CrossRef]

32. Wahsh, L.M.; ElShater, A.E.; Mansour, A.K.; Hamdy, F.A.; Turky, M.A.; Azzam, M.O.; Salem, H.G. Parameter Selection for Wire Arc Additive Manufacturing (Waam) Process. Mater. Sci. Technol. 2018. [CrossRef]

33. Kumar, C.B.; Anandakrishnan, V. Experimental investigations on the effect of wire arc additive manufacturing process parameters on the layer geometry of Inconel 825. Mater. Today Proc. 2020, 21, 622-627. [CrossRef]

34. Su, C.; Chen, X.; Gao, C.; Wang, Y. Effect of heat input on microstructure and mechanical properties of Al-Mg alloys fabricated by WAAM. Appl. Surf. Sci. 2019, 486, 431-440. [CrossRef]

35. Zhou, Y.; Lin, X.; Kang, N.; Huang, W.; Wang, J.; Wang, Z. Influence of travel speed on microstructure and mechanical properties of wire + arc additively manufactured 2219 aluminum alloy. J. Mater. Sci. Technol. 2020, 37, 143-153. [CrossRef]

36. Xiong, J.; Zhang, G. Adaptive control of deposited height in GMAW-based layer additive manufacturing. J. Mater. Process. Technol. 2014, 214, 962-968. [CrossRef]

37. Artaza, T.; Alberdi, A.; Murua, M.; Gorrotxategi, J.; Frías, J.; Puertas, G.; Melchor, M.; Mugica, D.; Suárez, A. Design and integration of WAAM technology and in situ monitoring system in a gantry machine. Procedia Manuf. 2017, 13, 778-785. [CrossRef]

38. Anikin, P.; Shilo, G.; Kulykovskyi, R.; Molochkov, D. Wire+ Arc Additive Manufacturing Automation Control System Architecture. In Proceedings of the Measuring and Computing Technology in Technological Processes Conference, Odessa, Ukraine, 26-29 June 2020; pp. 7-9.

39. Silva, R.; Barbosa, G.; Carvalho, J. Additive Manufacturing of Metal Parts by Welding. IFAC-PapersOnLine 2015, 48, 2318-2322. [CrossRef]

40. Xiong, J.; Lei, Y.; Li, R. Finite element analysis and experimental validation of thermal behavior for thin-walled parts in GMAW-based additive manufacturing with various substrate preheating temperatures. Appl. Therm. Eng. 2017, 126, 43-52 [CrossRef]

41. Radel, S.; Bordreuil, C.; Soulie, F.; Company, O. CAM for On-line Control for Wire Arc Additive Manufacturing. Comput. Des. Appl. 2018, 16. [CrossRef]

42. Ali, Y.; Henckell, P.; Hildebrand, J.; Reimann, J.; Bergmann, J.; Barnikol-Oettler, S. Wire arc additive manufacturing of hot work tool steel with CMT process. J. Mater. Process. Technol. 2019, 269, 109-116. [CrossRef]

43. Derekar, K.S.; Addison, A.; Joshi, S.S.; Zhang, X.; Lawrence, J.; Xu, L.; Melton, G.; Griffiths, D. Effect of pulsed metal inert gas (pulsed-MIG) and cold metal transfer (CMT) techniques on hydrogen dissolution in wire arc additive manufacturing (WAAM) of aluminium. Int. J. Adv. Manuf. Technol. 2020, 107, 311-331. [CrossRef]

44. Ortega, A.G.; Galvan, L.C.; Deschaux-Beaume, F.; Rouquette, S. Effect of welding parameters on the quality of multilayer deposition of aluminum alloy. Adv. Mater. Process. Technol. Conf. 2017, 23, 316-332. [CrossRef]

45. Ryan, E.; Sabin, T.; Watts, J.; Whiting, M. The influence of build parameters and wire batch on porosity of wire and arc additive manufactured aluminium alloy 2319. J. Mater. Process. Technol. 2018, 262, 577-584. [CrossRef]

46. Brandl, E.; Michailov, V.; Viehweger, B.; Leyens, C. Deposition of Ti-6Al-4V using laser and wire, part I: Microstructural properties of single beads. Surf. Coat. Technol. 2011, 206, 1120-1129. [CrossRef]

47. Ma, Y.; Cuiuri, D.; Shen, C.; Li, H.; Pan, Z. Effect of interpass temperature on in-situ alloying and additive manufacturing of titanium aluminides using gas tungsten arc welding. Addit. Manuf. 2015, 8, 71-77. [CrossRef]

48. Huang, J.; Liu, S.; Yu, S.; Yu, X.; Chen, H.; Fan, D. Arc deposition of wear resistant layer TiN on Ti6Al4V using simultaneous feeding of nitrogen and wire. Surf. Coatings Technol. 2020, 381, 125141. [CrossRef]

49. Wang, J.; Lin, X.; Li, J.; Hu, Y.; Zhou, Y.; Wang, C.; Li, Q.; Huang, W. Effects of deposition strategies on macro/microstructure and mechanical properties of wire and arc additive manufactured Ti6Al4V. Mat Sci. Eng. A. 2019, 754, 735-749. [CrossRef]

50. Wang, J.; Pan, Z.; Cuiuri, D.; Li, H. Phase constituent control and correlated properties of titanium aluminide intermetallic alloys through dual-wire arc additive manufacturing. Mater. Lett. 2019, 242, 111-114. [CrossRef]

51. Geng, H.; Li, J.; Xiong, J.; Lin, X.; Zhang, F. Geometric Limitation and Tensile Properties of Wire and Arc Additive Manufacturing 5A06 Aluminum Alloy Parts. J. Mater. Eng. Perform. 2016, 26, 621-629. [CrossRef]

52. Horgar, A.; Fostervoll, H.; Nyhus, B.; Ren, X.; Eriksson, M.; Akselsen, O. Additive manufacturing using WAAM with AA5183 wire. J. Mater. Process. Technol. 2018, 259, 68-74. [CrossRef]

53. Qi, Z.; Cong, B.; Qi, B.; Sun, H.; Zhao, G.; Ding, J. Microstructure and mechanical properties of double-wire + arc additively manufactured Al-Cu-Mg alloys. J. Mater. Process. Technol. 2018, 255, 347-353. [CrossRef]

54. Gu, J.; Yang, S.; Gao, M.; Bai, J.; Zhai, Y.; Ding, J. Micropore evolution in additively manufactured aluminum alloys under heat treatment and inter-layer rolling. Mater. Des. 2020, 186, 108288. [CrossRef] 
55. Li, C.; Gu, H.; Wang, W.; Wang, S.; Ren, L.; Wang, Z.; Ming, Z.; Zhai, Y. Effect of Heat Input on Formability, Microstructure, and Properties of Al-7Si-0.6Mg Alloys Deposited by CMT-WAAM Process. Appl. Sci. 2019, 10, 70. [CrossRef]

56. Qi, Z.; Qi, B.; Cong, B.; Sun, H.; Zhao, G.; Ding, J. Microstructure and mechanical properties of wire + arc additively manufactured 2024 aluminum alloy components: As-deposited and post heat-treated. J. Manuf. Process. 2019, 40, 27-36. [CrossRef]

57. Ünsal, I.; Hirtler, M.; Sviridov, A.; Bambach, M. Material Properties of Features Produced from EN AW 6016 by Wire-Arc Additive Manufacturing. Procedia Manuf. 2020, 47, 1129-1133. [CrossRef]

58. Wang, S.; Gu, H.; Wang, W.; Li, C.; Ren, L.; Wang, Z.; Zhai, Y.; Ma, P. The Influence of Heat Input on the Microstructure and Properties of Wire-Arc-Additive-Manufactured Al-Cu-Sn Alloy Deposits. Metals 2020, 10, 79. [CrossRef]

59. Yang, X.; Liu, J.; Wang, Z.; Lin, X.; Liu, F.; Huang, W.; Liang, E. Microstructure and mechanical properties of wire and arc additive manufactured AZ31 magnesium alloy using cold metal transfer process. Mater. Sci. Eng. A 2020, 774, 138942. [CrossRef]

60. Ge, J.; Lin, J.; Chen, Y.; Lei, Y.; Fu, H. Characterization of wire arc additive manufacturing 2Cr13 part: Process stability, microstructural evolution, and tensile properties. J. Alloy Compd. 2018, 748, 911-921. [CrossRef]

61. Xu, X.; Ganguly, S.; Ding, J.; Seow, C.E.; Williams, S. Enhancing mechanical properties of wire + arc additively manufactured INCONEL 718 superalloy through in-process thermomechanical processing. Mater. Des. 2018, 160, 1042-1051. [CrossRef]

62. Seow, C.E.; Coules, H.; Wu, G.; Khan, R.H.; Xu, X.; Williams, S. Wire + Arc Additively Manufactured Inconel 718: Effect of post-deposition heat treatments on microstructure and tensile properties. Mater. Des. 2019, 183, 108157. [CrossRef]

63. Yangfan, W.; Xizhang, C.; Chuanchu, S. Microstructure and mechanical properties of Inconel 625 fabricated by wire-arc additive manufacturing. Surf. Coatings Technol. 2019, 374, 116-123. [CrossRef]

64. Marinelli, G.; Martina, F.; Ganguly, S.; Williams, S. Development of Wire + Arc additive manufacture for the production of large-scale unalloyed tungsten components. Int. J. Refract. Met. Hard Mater. 2019, 82, 329-335. [CrossRef]

65. Marinelli, G.; Martina, F.; Ganguly, S.; Williams, S. Microstructure, hardness and mechanical properties of two different unalloyed tantalum wires deposited via wire + arc additive manufacture. Int. J. Refract. Met. Hard Mater. 2019, 83, 104974. [CrossRef]

66. Wang, Y.; Chen, X.; Konovalov, S.; Su, C.; Siddiquee, A.N.; Gangil, N. In-situ wire-feed additive manufacturing of Cu-Al alloy by addition of silicon. Appl. Surf. Sci. 2019, 487, 1366-1375. [CrossRef]

67. Haden, C.V.; Zeng, G.; Carter, F.M., III; Ruhl, C.; Krick, B.A.; Harlow, D.G. Wire and arc additive manufactured steel: Tensile and wear properties. Addit. Manuf. 2017, 16, 115-123. [CrossRef]

68. Feng, Y.; Zhan, B.; He, J.; Wang, K. The double-wire feed and plasma arc additive manufacturing process for deposition in Cr-Ni stainless steel. J. Mater. Process. Technol. 2018, 259, 206-215. [CrossRef]

69. Wang, L.; Xue, J.; Wang, Q. Correlation between arc mode, microstructure, and mechanical properties during wire arc additive manufacturing of 316L stainless steel. Mater. Sci. Eng. A 2019, 751, 183-190. [CrossRef]

70. Dirisu, P.; Supriyo, G.; Martina, F.; Xu, X.; Williams, S. Wire plus arc additive manufactured functional steel surfaces enhanced by rolling. Int. J. Fatigue 2020, 130, 105237. [CrossRef]

71. Suryakumar, S.; Karunakaran, K.; Bernard, A.; Chandrasekhar, U.; Raghavender, N.; Sharma, D. Weld bead modeling and process optimization in Hybrid Layered Manufacturing. Comput. Des. 2011, 43, 331-344. [CrossRef]

72. Ding, D.; Pan, Z.; Cuiuri, D.; Li, H. A multi-bead overlapping model for robotic wire and arc additive manufacturing (WAAM). Robot. Comput. Manuf. 2015, 31, 101-110. [CrossRef]

73. Geng, H.; Li, J.; Xiong, J.; Lin, X. Optimisation of interpass temperature and heat input for wire and arc additive manufacturing 5A06 aluminium alloy. Sci. Technol. Weld. Join. 2017, 22, 472-483. [CrossRef]

74. Guo, Y.; Zhao, Z.; Han, J.; Bai, L. Quality Monitoring in Wire-Arc Additive Manufacturing Based on Spectrum. In Proceedings of the 2018 the 2nd International Conference on Video and Image Processing, ICVIP 2018, Hong Kong, China, 18-21 December 2018; pp. 240-244.

75. Ríos, S.; Colegrove, P.; Martina, F.; Williams, S.W. Analytical process model for wire + arc additive manufacturing. Addit. Manuf. 2018, 21, 651-657. [CrossRef]

76. Tian, H.; Lu, Z.; Li, F.; Chen, S. Predictive Modeling of Surface Roughness Based on Response Surface Methodology after WAAM; Atlantis Press: Paris, France, 2019; pp. 47-50.

77. Teja, K.; Tokala, S.C.V.; Reddy, Y.P.; Narayana, K.L. Optimization of mechanical properties of wire arc additive manufactured specimens using grey-based taguchi method. J. Crit. Rev. 2020, 7, 808-817.

78. Lee, S.H. Optimization of Cold Metal Transfer-Based Wire Arc Additive Manufacturing Processes Using Gaussian Process Regression. Metals 2020, 10, 461. [CrossRef]

79. Hejripour, F.; Valentine, D.T.; Aidun, D.K. Study of mass transport in cold wire deposition for Wire Arc Additive Manufacturing. Int. J. Heat Mass Transf. 2018, 125, 471-484. [CrossRef]

80. Hejripour, F.; Binesh, F.; Hebel, M.; Aidun, D.K. Thermal modeling and characterization of wire arc additive manufactured duplex stainless steel. J. Mater. Process. Technol. 2019, 272, 58-71. [CrossRef]

81. Li, Y.; Sun, Y.; Han, Q.; Zhang, G.; Horváth, I. Enhanced beads overlapping model for wire and arc additive manufacturing of multi-layer multi-bead metallic parts. J. Mater. Process. Technol. 2018, 252, 838-848. [CrossRef]

82. Li, Y.; Huang, X.; Horváth, I.; Zhang, G. GMAW-based additive manufacturing of inclined multi-layer multi-bead parts with flat-position deposition. J. Mater. Process. Technol. 2018, 262, 359-371. [CrossRef]

83. Geng, H.; Li, J.; Xiong, J.; Lin, X.; Zhang, F. Optimization of wire feed for GTAW based additive manufacturing. J. Mater. Process. Technol. 2017, 243, 40-47. [CrossRef] 
84. Oyama, K.; Diplas, S.; M'Hamdi, M.; Gunnæs, A.E.; Azar, A.S. Heat source management in wire-arc additive manufacturing process for Al-Mg and Al-Si alloys. Addit. Manuf. 2019, 26, 180-192. [CrossRef]

85. Montevecchi, F.; Venturini, G.; Grossi, N.; Scippa, A.; Campatelli, G. Heat accumulation prevention in Wire-Arc-AdditiveManufacturing using air jet impingement. Manuf. Lett. 2018, 17, 14-18. [CrossRef]

86. Li, X.; Reynolds, A.P.; Baoqiang, C.; Jialuo, D.; Williams, S. Production and properties of a wire-arc additive manufacturing part made with friction extruded wire. In Proceedings of the TMS 2015 144th Annual Meeting \& Exhibition, Orlando, FL, USA, 15-19 March 2015; Springer: Cham, Germany, 2015; pp. 445-452.

87. Dharmendra, C.; Shakerin, S.; Ram, G.J.; Mohammadi, M. Wire-arc additive manufacturing of nickel aluminum bronze/stainless steel hybrid parts - Interfacial characterization, prospects, and problems. Materialia 2020, 13, 100834. [CrossRef]

88. Venturini, G.; Montevecchi, F.; Scippa, A.; Campatelli, G. Optimization of WAAM Deposition Patterns for T-crossing Features. Procedia CIRP 2016, 55, 95-100. [CrossRef]

89. Martina, F.; Roy, M.J.; Szost, B.A.; Terzi, S.; Colegrove, P.A.; Williams, S.W.; Withers, P.J.; Meyer, J.; Hofmann, M. Residual stress of as-deposited and rolled wire+ arc additive manufacturing Ti-6Al-4V components. Mater. Sci. Technol. 2016, 32, 1439-1448. [CrossRef]

90. Zhang, C.; Gao, M.; Zeng, X. Workpiece vibration augmented wire arc additive manufacturing of high strength aluminum alloy. J. Mater. Process. Technol. 2019, 271, 85-92. [CrossRef]

91. Hönnige, J.; Colegrove, P.; Ahmad, B.; Fitzpatrick, M.; Ganguly, S.; Lee, T.; Williams, S. Residual stress and texture control in Ti-6Al-4V wire + arc additively manufactured intersections by stress relief and rolling. Mater. Des. 2018, 150, 193-205. [CrossRef]

92. Wu, B.; Pan, Z.; Chen, G.; Ding, D.; Yuan, L.; Cuiuri, D.; Li, H. Mitigation of thermal distortion in wire arc additively manufactured Ti6Al4V part using active interpass cooling. Sci. Technol. Weld. Join. 2019, 24, 484-494. [CrossRef]

93. Gu, J.; Bai, J.; Ding, J.; Williams, S.; Wang, L.; Liu, K. Design and cracking susceptibility of additively manufactured Al-Cu-Mg alloys with tandem wires and pulsed arc. J. Mater. Process. Technol. 2018, 262, 210-220. [CrossRef]

94. Näsström, J.; Brueckner, F.; Kaplan, A.F.H. Laser enhancement of wire arc additive manufacturing. J. Laser Appl. 2019, $31,022307$. [CrossRef]

95. Corradi, D.R.; Bracarense, A.Q.; Wu, B.; Cuiuri, D.; Pan, Z.; Li, H. Effect of Magnetic Arc Oscillation on the geometry of single-pass multi-layer walls and the process stability in wire and arc additive manufacturing. J. Mater. Process. Technol. 2020, $283,116723$. [CrossRef]

96. Hauser, T.; Da Silva, A.; Reisch, R.T.; Volpp, J.; Kamps, T.; Kaplan, A.F. Fluctuation effects in Wire Arc Additive Manufacturing of aluminium analysed by high-speed imaging. J. Manuf. Process. 2020, 56, 1088-1098. [CrossRef]

97. Reisgen, U.; Sharma, R.; Mann, S.; Oster, L. Increasing the manufacturing efficiency of WAAM by advanced cooling strategies. Weld. World 2020, 64, 1409-1416. [CrossRef] 